NBER WORKING PAPER SERIES

\title{
DECLINING DESIRE TO WORK AND DOWNWARD TRENDS IN UNEMPLOYMENT AND PARTICIPATION
}

\author{
Regis Barnichon \\ Andrew Figura \\ Working Paper 21252 \\ http://www.nber.org/papers/w21252
NATIONAL BUREAU OF ECONOMIC RESEARCH
1050 Massachusetts Avenue
Cambridge, MA 02138
June 2015

We would like to thank Martin Eichenbaum and Jonathan Parker (the editors), Robert Hall and Richard Rogerson (our discussants) as well as Vladimir Asriyan, Vasco Carvalho, Davide Debortoli, Chris Foote, Bart Hobijn, Andreas Hornstein, Chris Nekarda, Kris Nimark, Nicolas Petrosky-Nadeau, Thijs van Rens, Martin Schneider, Justin Wolfers and Yanos Zylberberg for helpful comments. We also thank Roger Gomis, Erik Larsson, and Sebastien Willis for excellent research assistance. The views expressed here do not necessarily reflect those of the Federal Reserve Board or of the Federal Reserve System. Barnichon acknowledges financial support from the Spanish Ministerio de Economia y Competitividad (grant ECO2011-23188), the Generalitat de Catalunya (grants 2009SGR1157 and 2011BPB00152) and the Barcelona GSE Research Network. Any errors are our own. The views expressed herein are those of the authors and do not necessarily reflect the views of the National Bureau of Economic Research.

NBER working papers are circulated for discussion and comment purposes. They have not been peerreviewed or been subject to the review by the NBER Board of Directors that accompanies official NBER publications.

(C) 2015 by Regis Barnichon and Andrew Figura. All rights reserved. Short sections of text, not to exceed two paragraphs, may be quoted without explicit permission provided that full credit, including $\odot$ notice, is given to the source. 
Declining Desire to Work and Downward Trends in Unemployment and Participation Regis Barnichon and Andrew Figura

NBER Working Paper No. 21252

June 2015

JEL No. E24,J6

\begin{abstract}
$\underline{\text { ABSTRACT }}$
This paper argues that a key aspect of the US labor market is the presence of time-varying heterogeneity across nonparticipants. We document a decline in the share of nonparticipants who report wanting to work, and we argue that that decline, which was particularly strong in the second half of the $90 \mathrm{~s}$, is a major aspect of the downward trends in unemployment and participation over the past 20 years. A decline in the share of "want to work" nonparticipants lowers both the participation rate and the unemployment rate, because a nonparticipant who wants to work has (i) a higher probability of entering the labor force (compared to other nonparticipants), and (ii) a higher probability of joining unemployment conditional on entering the labor force. We use cross-sectional variation to estimate a model of nonparticipants' propensity to want to work, and we find that changes in the provision of welfare and social insurance, possibly linked to the mid-90s welfare reforms, explain about 50 percent of the decline in desire to work among nonparticipants.
\end{abstract}

Regis Barnichon

CREI and Universitat Pompeu Fabra

Ramon Trias Fargas, 25-27

08005 Barcelona

SPAIN

rbarnichon@crei.cat

Andrew Figura

Federal Reserve Board

20th Street and Constitution Avenue N.W.

Washington, DC 20551

andrew.figura@frb.gov

A data appendix is available at:

http://www.nber.org/data-appendix/w21252 


\section{Introduction}

The US labor market has witnessed two remarkable secular trends in the last 30 years. First, the unemployment rate declined secularly after the early $80 \mathrm{~s}$, prompting policy makers to adjust downward their estimate of the natural rate or NAIRU (Non-Accelerating Inflation Rate of Unemployment), as shown in Figure 1. Second, a decline in labor force participation has brought down the participation rate to a level not seen in 30 years (Figure 2).

However, considerable uncertainty remains about the underlying reasons for these trends. While the aging of the baby boom generation has often been cited as a possible factor, ${ }^{1}$ it is not clear that demographics alone is responsible for these trends. This uncertainty is best illustrated with the recent lively debate about the "cyclical" or "structural" nature (i.e., persistence) of the low participation rate observed today. ${ }^{2}$

This paper argues that a key, but so far little studied, aspect of the secular changes witnessed by the US labor market is the presence of time-varying heterogeneity across nonparticipants (individuals outside the labor force), i.e., changes in the composition of the nonparticipation pool. We document a strong decline in desire to work among nonparticipants in the second half of the 90s, and we show that that decline is a major aspect of the downward trends in unemployment and participation over the past 20 years.

The Current Population Survey (CPS) has been measuring individuals' desire for work consistently since 1967, allowing us to construct a measure of nonemployed individuals' desire to work over 1967-2014. We find that the share of nonparticipants who want to work has been declining secularly over the past 30 years, with a particularly strong decline during the second half of the $90 \mathrm{~s}$.

A downward trend in the share of nonparticipants who want a job has consequences for the aggregate unemployment and participation rates, because people who want a job behave differently from people who do not want a job. Using matched CPS micro data to measure worker transitions between labor market states, we find that a nonparticipant who wants a job enters the labor force (i) often and (ii) mostly through unemployment, while a nonparticipant who does not want a job enter the labor force (i) rarely and (ii) mostly through employment. Because of this difference in behavior, a decline in the fraction of nonparticipants who want a job lowers both the unemployment rate and the participation rate. We develop a stock-flow accounting framework to quantify this effect, and we find that the decline in nonparticipants'

\footnotetext{
${ }^{1}$ Since older workers have lower unemployment and participation rates than younger workers, an older population will have both lower unemployment and participation rates. The aging of the baby boom generation has been proposed to explain the inverse U-shape movement in unemployment since the early 70s (Perry (1970), Flaim (1979), Gordon (1982), Summers (1986), and Shimer (1998, 2001)).

${ }^{2}$ See, e.g., Aaronson et al. (2012), Elsby and Shapiro (2012), Moffitt (2012), Sherk (2012), Van Zandweghe (2012), Erceg and Levin (2013), Hotchkiss, Pitts and Rios-Avila (2013).
} 
desire to work since the mid-90s lowered the unemployment rate by about $0.5 \mathrm{ppt}$ and the participation rate by $1.75 \mathrm{ppt}$. This is a large effect: in comparison, the widely studied aging of the baby boom lowered unemployment by $0.7 \mathrm{ppt}$ and participation by $2.5 \mathrm{ppt}$ over the same time period. Taken together, population aging and variations in the share of "want a job" nonparticipants can account for the bulk of the low-frequency movements in unemployment since the late 60 s.

We conclude that a better understanding of the characteristics of individuals outside the labor force is crucial to understand the trends in unemployment and participation, and in the second part of the paper, we explore possible explanations for the decline in nonparticipants' desire to work in the second half of the $90 \mathrm{~s}$.

Looking across different sub-groups, the decline in the number of nonparticipants who want to work is due mainly to prime-age females, and, to a lesser extent, young individuals. Moreover, the decline is mainly a low-income and non-single household phenomenon (with virtually no decline in desire to work among single households), and is stronger for families with children than without.

We estimate a model of nonparticipants' propensity to want a job, in which desire to work can depend on individual characteristics, the family structure, as well as the different sources of income, both at the individual and at the family level. We use time fixed effects, so that our coefficient estimates depend on cross sectional variation, and we use our estimates to predict changes in desire to work since the mid-90s.

Our estimates imply that changes in the provision of (i) welfare insurance and (ii) social insurance (mainly disability) explain about 50 percent of the decline in the share of "want a job" nonparticipants. This finding suggests a possible role for the major welfare reforms of the 90s -the 1993 Earned Income Tax Credit (EITC) expansion and the 1996 reform of the Aid to Families with Dependent Children (AFDC) program-, which precisely affected low-income households with children.

We then use a difference-in-difference strategy to try to identify the causal effects of the EITC expansion and the AFDC reform on low-income mothers. The strategy exploits the facts that households without children receive little EITC or AFDC benefits and were therefore little affected by the reforms. The difference-in-difference estimates attribute between 50 and 70 percent of the decline in mothers' desire to work to the welfare reforms. In other words, the welfare reforms pushed some nonparticipants further away from the labor force. Thus, while the "welfare to work" reform -designed to strengthen the incentives to work and to bring welfare recipients into the labor force- is generally considered to have been successful in bringing many nonparticipants into the labor force (Blank, 2002), our results imply that the effect of the reform may have been more subtle than previously thought. For some nonparticipants, 
the reform appears to have had the opposite of the intended effect.

Although the existence of different degrees of desire to work among nonparticipants has been previously documented (Hall 1970, Clark and Summers, 1979), the existence of a secular trend in desire to work and its effects on the participation and unemployment rates are, as far as we know, novel. Moreover, the effect of nonparticipants' characteristics on the aggregate unemployment rate measure underscores the difficult issue of the appropriate definition of unemployment and the distinction between the "unemployment" and "out of the labor force" classifications (Clark and Summers 1979, Flinn and Heckman, 1983, Jones and Riddell, 1999).

To quantify how the decline in desire to work affects unemployment and participation, we build on a large literature, going back at least to Darby, Haltiwanger and Plant (1986), that studies the flows of workers in and out of unemployment. ${ }^{3}$

Finally, the possibility that changes in the provision of social transfers can affect desire to work and thereby the aggregate unemployment and participation rates echoes Juhn, Murphy and Topel (2002) and Autor and Dugan (2003) who argue that the growing attractiveness of disability benefits relative to work increased the number of individuals outside the labor force.

Section 2 documents the decline in the fraction of nonparticipants willing to work; Section 3 quantifies how the decline in nonparticipants willing to work affects the unemployment and participation rates; Section 4 discusses the robustness of our results; Sections 5 explores the possible reasons for the decline in desire to work; Section 6 concludes.

\section{Fewer people want to work}

In this section, we show that the fraction of nonparticipants who report "wanting to work" has displayed substantial secular movements, with a particularly strong decline during the second half of the $90 \mathrm{~s}$.

\section{1 "Do you want a job now?"}

To measure the extent to which nonemployed individuals are interested in working, we use data collected by the BLS. Since 1967, the Current Population Survey (CPS) has been consistently asking the question "Do you currently want a job now, either full or part-time?" to nonemployed individuals outside the labor force, also called "nonparticipants". We use the answer to this question to separate nonparticipants into two groups; nonparticipants who want a job, denoted $N^{w}$ and nonparticipants who do not want a job, denoted $N^{n}$.

\footnotetext{
${ }^{3}$ See, among others, Blanchard and Diamond (1989, 1990), Bleakley, Ferris and Fuhrer (1999), Jones and Riddell (1999), Elsby, Michaels and Solon (2009), Fujita and Ramey (2009), Barnichon (2012), Shimer (2012), and Elsby, Hobijn and Sahin (2013).
} 
Since the phrasing of the CPS question did not change over 1967-2014, we can construct a consistent time-series of the share of nonparticipants who want to work over 1976-2014; i.e., the ratio

$$
m_{t} \equiv \frac{N_{t}^{w}}{N_{t}^{w}+N_{t}^{n}}
$$

with $N_{t}^{w}$ and $N_{t}^{n}$ the respective number of "want a job" and "not want a job" nonparticipants. For the period covering 1967-1975, we tabulated the data from successive BLS Employment and Earnings publications, and for the period covering 1976-2014, we used micro data from the CPS.

Figure 3 shows that the fraction of "want a job" nonparticipants $\left(m_{t}\right)$ displays an inverse U-shape pattern over over 1967-2014, with a particularly strong decline in the second half of the 90s. ${ }^{4,5}$ Interestingly, the behavior of the Congressional Budget Office (CBO)'s estimate of the natural rate -one estimate of the long-run level of unemployment- displays a pattern that is similar to that of $m_{t}$., a point to which we will later return. ${ }^{6}$

\section{2 "Want a job" vs. "Not want a job"}

While the trend in the share of "want a job" nonparticipants is striking, for it to be of any consequence for the aggregate labor market, people who want to work must behave differently from people who do not want to work.

To evaluate whether this is the case, we match the CPS micro data over 1994-2010 to measure and compare the transition rates of nonparticipants who report wanting a job (denoted $N^{w}$ ) with the transition rates of nonparticipants who report wanting a job (denoted $\left.N^{n}\right){ }^{7}$

Figure 4 shows a representation of the labor market with three states -Employment (E), Unemployment (U) and Nonparticipation (N)-, and reports the average monthly transition rates out of Nonparticipation (either to E or U) for "want a job" nonparticipants $\left(N^{w}\right)$ and "not want a job" nonparticipants $\left(N^{n}\right)$.

\footnotetext{
${ }^{4}$ There is a subtle difference in the survey before and after 1994. While the "desire for work" question is asked to all rotation groups after 1994, it is only asked to the outgoing rotation groups before 1994, i.e., 1/4 of the sample. We verified that this difference did not affect our measurement, by calculating the fraction of marginally-attached using only the outgoing rotation groups over the whole sample 1976-2010, and compared it with our main measure. Although this alternative measure is more noisy, the two series behave remarkably similarly after 1994 .

${ }^{5}$ To assess the robustness of our finding, we use another, little studied, CPS question that has also been consistently asked since 1976: "Do you intend to look for work during the next 12 months?". That measure also displays a marked decline in the second half of the 1990s.

${ }^{6}$ Although not the focus of this paper, it is also interesting to note that desire to work among nonparticipants is strongly counter-cyclical.

${ }^{7}$ See the Appendix for details on the construction of these series, in particular the time-aggregation bias correction. Since the question about "desire for work" was only asked to the outgoing rotation groups prior to 1994, we cannot measure worker flows in and out of $N^{w}$ or $N^{n}$ prior to 1994, because we do not observe the labor force status over two consecutive months.
} 
We can see that someone who wants a job behaves very differently from someone who does not want a job.

First, someone who wants a job $\left(N^{w}\right)$ is very likely to enter the labor force in the near future $\left(\lambda^{N^{w} U}+\lambda^{N^{w} E}=.62\right.$, where $\lambda^{A B}$ denotes the average transition rate from state $A \in$ $\left\{E, U, N^{w}, N^{n}\right\}$ to state $\left.B \in\left\{E, U, N^{w}, N^{n}\right\}\right)$. In other words, someone who wants a job is at the margin of participation. In contrast, someone who does not want a job $\left(N^{n}\right)$ is unlikely to enter the labor force in the near future $\left(\lambda^{N^{n} U}+\lambda^{N^{n} E}=.05\right)$ and is thus "far" from the participation margin and from labor force activity.

Second, a "want a job" nonparticipant is much more likely to enter the labor force through unemployment than through employment $\left(\lambda^{N^{w} U}>\lambda^{N^{w} E}\right)$, but this is the opposite for a "not want a job" nonparticipant: someone who does not want a job is much more likely to enter the labor force through employment $\left(\lambda^{N^{n} E}>\lambda^{N^{n} U}\right)$. These two differences in behavior between "want a job" and "not want a job" nonparticipants -the fact that $\lambda^{N^{w} U}-\lambda^{N^{w} E}>0$ and $\lambda^{N^{n} E}-\lambda^{N^{n} U}>0$ - will later prove crucial, when we consider how changes in the share of "want a job" nonparticipants affect the unemployment rate.

To dig a little deeper, we study whether a difference between "want a job" and "not want a job" nonparticipants continues to exist once nonparticipants enter the labor force. Table 1 compares the transition rates of recent (entered a month ago) labor force entrants with the transition rates of other labor force participants (who entered the labor force more than a month ago). ${ }^{8}$ We can see that recent labor force entrants have much higher transition rates back to nonparticipation. However, although "want a job" and "not want a job" nonparticipants display very different transition rates into participation (Figure 4), the difference is much less marked once these individuals are inside the labor force. Table 1 shows that their job finding rates are similar and that their labor force exit rate are somewhat comparable. Interestingly, a former "not want a job" $\left(N^{n}\right)$ is more likely to leave the labor force than a former "want a job" $\left(N^{w}\right)$.

\subsection{The fraction of "want a job" across demographic groups}

Looking at different demographics, a decline in the share of "want a job" nonparticipants can be seen among prime-age females, prime-age males and young workers. However, in terms of the number of individuals affected by the decline, the decline is mainly a prime-age female, and to a lesser extent young worker, phenomenon.

First, similarly to Figure 3, Figure 5 plots $m_{i t}$, the fraction of "want a job" nonparticipants for four demographic subgroups (denoted with the subscript $i$ ): Prime-age male 25-55, Prime-

\footnotetext{
${ }^{8}$ To do so, we match CPS micro data over three consecutive surveys (see Nekarda, 2009), and we adjust the transition probabilities for time-aggregation bias as described in the Appendix.
} 
age female 25-55, Younger than 25 and Over 55. In all groups except for old workers, $m_{i t}$ displays an inverted-U shape, rising in the 70 s and declining in the second-half of the $90 \mathrm{~s}^{9}{ }^{9}$

However these percentage point declines hide large differences in the number of individuals affected by the decline in desire to work. Between 1994 and 2001, the number of primeage female willing to work declined by 930,000, of young individuals by 680,000 , and the number of prime-age male declined by "only" 250,000. Thus, the decline in desire to work is predominantly a (i) prime-age female, and (ii) young individuals phenomenon. This difference between groups was not apparent in the behavior of the share of "want a job" nonparticipants, because that measure does not capture differences in participation rates across groups. In particular, since prime-age males have a very high participation rate, there are few prime-age male nonparticipants, so that the decline in $m_{i t}$ is a phenomenon that affected only a very small share of the prime-age male population. This is not the case for prime age females and young individuals.

\section{Declining share of "want a job" and movements in unem- ployment and participation}

Given the marked differences in labor market behavior between "want a job" and "not want a job" individuals, movements in the share of "want a job" nonparticipants may affect the aggregate unemployment and participation rates. In this section, we use a stock-flow accounting framework to quantify these effects.

We make two points. First, the share of "want a job" nonparticipants is an important aspect of the inverse U-shape behavior of unemployment between the early 1970s and the early 2000s. Second, the decline in desire to work in the second-half of the 90 s is related to the currently low level of participation in the US.

\subsection{Some accounting}

Our starting point is a labor market described by four labor market states: Employment $(E)$, Unemployment $(U)$, Nonparticipant who wants a job $\left(N^{w}\right)$ and Nonparticipant who does not want a job $\left(N^{n}\right)$.

As in the "Ins and Outs" literature (e.g., Shimer, 2012), we assume that the labor market can be described by a Markov chain of order $1,{ }^{10}$ so that the number of employed $E_{t}$, unem-

\footnotetext{
${ }^{9}$ For young workers, the secular decline appears to go back to the early 80s, pointing to an older phenomenon.

${ }^{10}$ Since we found that the most striking difference between $N^{w}$ and $N^{n}$ individuals was in their transition rates into the labor force (and not their subsequent transition rates once inside the labor force), we assume that the labor market with 4 states can be described by a Markov chain of order 1 . In other words, once inside the
} 
ployed $U_{t}$, "want a job" nonparticipants $N_{t}^{w}$ and "not want a job" nonparticipants $N_{t}^{n}$ satisfies the system

$$
\left(\begin{array}{c}
\bullet \\
U \\
N^{w} \\
N^{n}
\end{array}\right)_{t}=\Lambda_{t}\left(\begin{array}{c}
E \\
U \\
N^{w} \\
N^{n}
\end{array}\right)_{t}
$$

with

$\Lambda_{t}=\left(\begin{array}{cccc}-\lambda^{E U}-\lambda^{E N^{w}}-\lambda^{E N^{n}} & \lambda^{U E} & \lambda^{N^{w} E} & \lambda^{N^{n} E} \\ \lambda^{E U} & -\lambda^{U E}-\lambda^{U N^{w}}-\lambda^{U N^{n}} & \lambda^{N^{w} U} & \lambda^{N^{n} U} \\ \lambda^{E N^{w}} & \lambda^{U N^{w}} & -\lambda^{N^{w} U}-\lambda^{N^{w} E}-\lambda^{N^{w} N^{n}} & \lambda^{N^{n} N^{w}} \\ \lambda^{E N^{n}} & \lambda^{U N^{n}} & \lambda^{N^{w} N^{n}} & -\lambda^{N^{n} U}-\lambda^{N^{n} E}-\lambda^{N^{n} N^{w}}\end{array}\right)_{t}$

and where $\lambda_{t}^{A B}$ denotes the hazard rate of transiting from state $A \in\left\{E, U, N^{w}, N^{n}\right\}$ to state $B \in\left\{E, U, N^{w}, N^{n}\right\}$.

We can then use (1) to express any stock variable, for instance the unemployment rate $u_{t}=\frac{U_{t}}{E_{t}+U_{t}}$ and the participation rate $l_{t}=\frac{L F_{t}}{P o p_{t}}$ with the population $\operatorname{Pop}_{t}=E_{t}+U_{t}+N_{t}^{w}+N_{t}^{n}$, as functions of the (present and past) worker transition rates $\left\{\lambda_{t-j}^{A B}, \forall j>0\right\}$. For the US, such functions are particularly simple, because the magnitude of the worker flows are so large that, at a quarterly frequency, the labor market is very well described by the steady-state of system (1). ${ }^{11}$ As detailed in the Appendix, the steady-state of system (1) then gives us an accounting identity that allows to express the unemployment rate $u_{t}$ and participation rate $l_{t}$ as functions $u($.$) and l($.$) of the 12$ contemporaneous hazard rates $\left\{\lambda_{t}^{A B}\right\}$.

Then, it is easy to write $u_{t}$ and $l_{t}$ as functions of the transition rates out of Employment $(E)$, Unemployment $(U)$, and Nonparticipation ( $N$, including all nonparticipants, $N^{w}$ or $N^{n}$ ) with

$$
\left\{\begin{array}{l}
u_{t}=u\left(\left\{\lambda_{t}^{A B}\right\}\right) \\
l_{t}=l\left(\left\{\lambda_{t}^{A B}\right\}\right)
\end{array}, \quad A, B \in\{E, U, N\}\right.
$$

where the N-U and N-E transition rates, denoted $\lambda_{t}^{N U}$ and $\lambda_{t}^{N E}$, are weighted averages of the

labor force, $N^{w}$ and $N^{n}$ individuals behave like the other labor force participants. In the appendix, we consider a richer model that allows $N^{w}$ and $N^{n}$ individuals to continue behaving differently once inside the labor force. The quantitative results are similar to what we report in the main text. This is because $N^{w}$ and $N^{n}$ individuals do not behave very differently once inside the labor force. Thus, a change in the ratio of $N^{w}$ and $N^{n}$ individuals affect the unemployment rate mostly through the differences in their labor force entry rates.

${ }^{11}$ In the U.S., the magnitudes of the hazard rates are such that the half-life of a deviation of unemployment from its steady state value is about one month (Shimer, 2012). 
two transition rates out of $N^{w}$ and $N^{n}$

$$
\left\{\begin{array}{l}
\lambda_{t}^{N U}=m_{t} \lambda_{t}^{N^{w} U}+\left(1-m_{t}\right) \lambda_{t}^{N^{n} U} \\
\lambda_{t}^{N E}=m_{t} \lambda_{t}^{N^{w} E}+\left(1-m_{t}\right) \lambda_{t}^{N^{n} E}
\end{array}\right.
$$

with the weight $m_{t}$ given by the share of "want a job" nonparticipants.

Since nonparticipants who want a job behave very differently from the nonparticipants who do not want a job (in particular, $\lambda^{N^{w} U}>>\lambda^{N^{n} U}$ ), changes in the fraction of nonparticipants who want a job will affect the transition rates out of Nonparticipation through (3) and thus the unemployment and participation rates through (2).

\subsection{Quantifying the effect of lower desire to work}

A Taylor expansion of the accounting identities (2) around the mean of the hazard rates $\left(\lambda_{t}^{A B} \simeq \lambda^{A B}\right)$ and a little bit of algebra with (3) gives (see the Appendix for more details) that the effect of a change in the fraction of "want a job" nonparticipants on the aggregate unemployment rate, denoted $d u_{t}^{m}$, is given by

$$
d u_{t}^{m}=\beta^{N U}\left[\left(\lambda^{N^{w} U}-\lambda^{N^{n} U}\right)-\frac{\lambda^{N U}}{\lambda^{N E}}\left(\lambda^{N^{w} E}-\lambda^{N^{n} E}\right)\right]\left(m_{t}-m\right)
$$

with $m$ the average fraction of "want a job" nonparticipants, and $\beta^{N U}>0$, the coefficient of the first-order Taylor expansion of $u_{t}$ with respect to $\lambda_{t}^{N U}$.

The effect of a decline in desire to work on the aggregate unemployment rate is a priori ambiguous. On the one hand, as captured by the first term on the right-hand side of (4), a decline in the share of "want a job" nonparticipants lower the average NU transition rate since "want a job" nonparticipants are more likely to join unemployment than "not want a job" nonparticipants $\left(\lambda^{N^{w} U}-\lambda^{N^{n} U}>0\right)$, and this lowers the unemployment rate. On the other hand, as captured by the second term on the right-hand side of (4), a decline in the share of "want a job" nonparticipants lowers the average N-E transition rate, since "want a job" nonparticipants are more likely to join employment $\left(\lambda^{N^{w} E}-\lambda^{N^{n} E}>0\right)$, and this increases the unemployment rate. In practice however, a lower share of nonparticipants who want to work unambiguously implies a lower unemployment rate. The two hazard rates out of nonparticipation, $\lambda^{N U}$ and $\lambda^{N E}$, are of similar magnitudes and $\frac{\lambda^{N U}}{\lambda^{N E}} \simeq 1$, so that the sign of the effect of a change in $m$ on the unemployment rate is given by

$$
\underbrace{\left(\lambda^{N^{w} U}-\lambda^{N^{w} E}\right)}_{>0}+\underbrace{\left(\lambda^{N^{n} E}-\lambda^{N^{n} U}\right)}_{>0}>0
$$


which is unambiguously positive for two reasons: (i) a nonparticipant who wants a job enters the labor force mainly through unemployment $\left(\lambda^{N^{w} U}-\lambda^{N^{w} E}>0\right)$, and (ii) a nonparticipant who does not want a job enters the labor force mostly through employment $\left(\lambda^{N^{n} E}-\lambda^{N^{n} U}>0\right)$.

To quantify the effect of changes in the fraction of "want a job" nonparticipants on the labor force participation rate, we proceed in the exact same fashion and calculate $d l_{t}^{m}$ from a relation similar to (4). Contrary to the unemployment rate, a decline in $m_{t}$ has an unambiguous effect on the labor force participation rate. Since a lower fraction of "want a job" nonparticipants lowers all transition rates out of Nonparticipation, a lower fraction of "want a job" nonparticipants implies a lower labor force participation rate.

\subsection{Controlling for demographic heterogeneity}

Before proceeding with the decomposition results, we generalize our approach to control for changes in demographics.

We do so for two reasons: First, changes in demographics are known to have large effects on the behavior of the unemployment and participation rates, and we want to put the effects of declining desire to work in the context of the contribution of demographics. Second, to the extent that declining average desire to work could be explained by changes in the demographic structure of the nonparticipation pool, we want to control for the demographic composition of the population.

We divide the population into $K=8$ demographic (age and sex) groups, denoted by subscript $i \in\{1, . ., K\} .{ }^{12}$ The approach to identify the effect of lower desire to work is exactly as described in the previous section, except that all variables now have a subscript $i$. As described in the Appendix, we can then aggregate across groups to estimate the effects of (i) demographics, and (ii) desire to work among nonparticipants, on the aggregate unemployment and participation rates by using the definitions

$$
\left\{\begin{array}{l}
u_{t}=\sum_{i=1}^{K} \omega_{i t} u_{i t} \\
l_{t}=\sum_{i=1}^{K} \Omega_{i t} l_{i t}
\end{array}\right.
$$

with $\omega_{i t}$ the labor force share of group $i$ and $\Omega_{i t}$ the population share of group $i$.

\footnotetext{
${ }^{12}$ Specifically, we split the population into the following 8 sex/age groups: 16 to 24 , male 25-34, male 35 -44, male 45-54, female 25-34, female 35-44, female 45-54, and 55 and over.
} 


\subsection{Decomposition of the unemployment rate}

We start by analyzing the behavior of the unemployment rate.

Figure 6 plots the contributions of (i) demographics (top panel) and (ii) the fraction of "want a job" nonparticipants (middle panel) to movements in unemployment. To help put results into perspective, we also plot the $\mathrm{CBO}$ estimate of the natural rate (dashed line) as a proxy for trend unemployment.

Demographics and the aging of the baby boom generation first increased unemployment until the late 70s. Then, between 1979 and 2006 demographics lowered unemployment by about 0.7 percentage point. However, demographics alone can account for only about half of the trend in unemployment and its inverse U-shape.

The decline in the share of "want a job" nonparticipants lowered the aggregate unemployment rate substantially: Comparing the business cycle peaks of 1979 and 2006, the decline in desire to work lowered the unemployment rate by about $0.5 \mathrm{ppt}$ over the last 30 years. This contribution is comparable with that of demographics.

Interestingly, taken together, demographics and desire to work among nonparticipants (bottom panel of Figure 6) appear to account for most of the low-frequency movements in unemployment, as captured by the CBO estimate of the natural rate.

Another way to make this point is to consider Figure 7. In that figure, we plot the result of a decomposition of the unemployment rate into its different flows (stripped of demographic effects). Specifically, we use our stock-flow accounting framework and accounting identity (2) to decompose the movements in the aggregate unemployment rate into the contributions of respectively, (i) demographics (first panel), (ii) the flows out of Nonparticipation (the $N U$ and $N E$ flows, second panel), (iii) the flows out of Employment (the $E U$ and $E N$ flows, third panel) and (iv) the flows out of Unemployment (the $U E$ and $U N$ flows, fourth panel). Summing up the four contributions gives the total change in the aggregate unemployment rate. In addition, in the second panel (dashed line), we plot the contribution of the share of "want a job" nonparticipants to movements in unemployment. We plot that contribution in the second panel -"Transitions out of N"-, because the share of "want a job" affects unemployment by modifying the transitions out of N. More details about the decomposition are provided in the Appendix.

We can see that the flows out of $\mathrm{E}$ or out of $\mathrm{U}$ display little trend and thus cannot be responsible for the secular movements in unemployment. Instead, demographics and the flows out of $\mathrm{N}$-the top two panels of Figure 7 - are responsible for the decline in unemployment since the early 80s. Moreover, the decline in the share of "want a job" nonparticipants appears to account for a significant fraction of the contribution of the flows out of $\mathrm{N}$. Thus, consistent with Figure 6, demographics and the share of "want a job" nonparticipants do seem to be the 
main factors behind the decline in unemployment since the mid-80s.

We conclude that understanding how the characteristics of the nonparticipants can change over time is crucial to better understand the behavior of long-run unemployment in the US.

\subsection{Decomposition of the labor force participation rate}

We now turn to analyzing the participation rate, and we provide two sets of results, as with the unemployment rate.

First, Figure 8 plots the contributions of (i) demographics (top panel) and (ii) the fraction of "want a job" nonparticipants (middle panel) to movements in participation. The bottom panel plots the total contribution of (i) and (ii). To help put results into perspective, we also plot the actual participation rate.

Second, Figure 9 plots the decomposition of the participation rate into its different flows (stripped of demographic effects): (i) demographics (first panel), (ii) the flows out of Nonparticipation (second panel), (iii) the flows out of Employment (third panel) and (iv) the flows out of Unemployment (fourth panel). Summing up the four contributions gives the total change in the aggregate participation rate. In addition, in the second panel (dashed line), we plot the contribution of the share of "want a job" nonparticipants to movements in participation. We plot that contribution in the second panel -"Transitions out of N"-, because the share of "want a job" affects participation by modifying the transitions out of $\mathrm{N}$.

Overall, demographics has had a small effect on participation since the late $60 \mathrm{~s}$, and it is only since the end of the last recession that the aging of the baby boom generation substantially lowered participation. ${ }^{13}$ In contrast, movements in the share of "want a job" appear to have substantially affected the participation rate over time. In particular, the decline in the share of "want a job" nonparticipants in the second half of the 90s lowered the participation rate by about $1 \frac{3}{4}$ ppt (second panel of Figure 8 or 9 ).

Putting demographics and desire for work together, the bottom panel of Figure 8 shows that demographics and the share of "want a job" account for most of the downward trend in participation since the early 2000s. There is currently a large debate on the reasons for the currently record low level of participation in the US. Our decomposition suggest that the low share of "want a job" nonparticipants is an important factor behind the currently low level of participation.

However, Figure 9 also shows that, unlike with the unemployment rate, other flows contributed to the secular movements in participation. In particular, flows out of Employment

\footnotetext{
${ }^{13}$ The contribution of demographics to the participation rate is mainly driven by the population share of old $(65+)$ workers (who have a much lower participation rate than the other groups), and the population share of $65+$ workers has started to increase markedly after 2007.
} 
(third panel) are responsible for the strong increase in participation in the 70s and 80s. Thus, we do not claim that demographics and "want a job" have always been major forces behind secular movements in participation. We will come back to this point in the next section.

\section{Discussion}

Our previous results indicate that variation in the characteristics of nonparticipants and specifically changes in the share of "want a job" nonparticipants has been a major factor in the trends in the unemployment and participation rates. In this section, we discuss two possible issues associated with our results. ${ }^{14}$ The first issue has to do with timing: the behavior of the participation rate does not line up well with the share of "want a job" nonparticipants, suggesting the absence of any relationship between the two series, and thus apparently contradicting our conclusions. The second issue relates to the way we quantified the effect of a change in the share of "want a job" nonparticipants on unemployment and participation by assigning to any $N^{w}$ or $N^{n}$ individual the average transition rate out of that state. In this section, we successively discuss these two concerns.

\subsection{Timing}

Our previous accounting exercise showed that the decline in the share of want a job had a substantial effect on both the unemployment and participation rates. However, while the lowfrequency behavior of unemployment lines up reasonably well with the behavior of the share of "want a job" nonparticipants (figure 3), which is consistent with our story, the participation rate shows no apparent correlation with the fraction of "want a job" nonparticipants (figure 8, middle panel). For instance, while participation displayed an inverse U-shaped pattern between 1980 and 2010, the share of "want a job" was roughly flat until the mid-90s and only then started to decline. This lack of correlation may seem surprising and could suggest some issue with our decomposition exercise.

However, we think that this conclusion would be too hasty. Many different forces have affected the participation rate over the past 45 years, so that the absence of any correlation between participation and one of the factors (in our case, the share of "want a job") is not necessarily a problem. ${ }^{15}$

First, an important factor behind the large increase in participation in the $70 \mathrm{~s}$ and $80 \mathrm{~s}$ is the increase in the participation rate of women (e.g., Abraham and Shimer, 2001). And indeed,

\footnotetext{
${ }^{14}$ We thank our discussants for pointing out these possible issues.

${ }^{15}$ Our point recalls that of Elsby et al. (2013), who show that the apparent acyclicality of the participation rate is in fact the result of off-setting worker flows.
} 
going back to our stock-flow decomposition of the participation rate, shown in Figure 9, we can see that the most important component behind the secular increase in participation during that time is a secular change in workers' transition rates out of Employment (third panel). ${ }^{16}$ This effect was very strong and dwarfed the contribution of the other flows.

Another powerful factor behind movements in the participation rate is workers' job finding rate. In strong labor markets, workers' job finding rate is high, and this raises the participation rate. This mechanism can be seen in the contribution of two flows: the job finding rate out of unemployment (UE) and the job finding rate out of nonparticipation (NE). ${ }^{17}$ For instance, in the second-half of the 90s, participation increased, because both the UE and NE rates reached historically high values. ${ }^{18}$

With these different forces affecting the participation rate through different flows, we conclude that one cannot reject the results of our quantitative decomposition from an inspection of the correlation between the participation rate and the share of "want a job" nonparticipants.

However, to evaluate the plausibility of our results, we can focus on the flows directly affected by the share of "want a job" (but little affected by the aforementioned factors). Since we saw in section 2 that the largest difference between "want a job" and "not want a job" Nonparticipants $(\mathrm{N})$ is their transition rate into Unemployment (U), we should observe a strong correlation between the share of "want a job" and the $\mathrm{N}$ to $\mathrm{U}$ transition rate. Figure 10 shows that this is indeed the case: the $\mathrm{N}$ to $\mathrm{U}$ transition rate displayed a marked decline in the second half of the 90s that coincides with the decline in the share of "want a job". In other words, the timing is consistent with our story.

\subsection{Average versus marginal change}

A more subtle and more difficult issue is the following: When we quantify the effect of a change in the share of "want a job" nonparticipants on the average transition rates out of Nonparticipation (N), equation (4) implicitly attributes to any $N^{w}$ or $N^{n}$ individual the average transition rate out of that state. As a result, as the share of "not want a job" nonparticipants increased in the late $90 \mathrm{~s}$, we posited that some average $N^{w}$ individuals (i.e., with very large transition rates out of $N$ ) became average $N^{n}$ individuals (with very small transition rates out

\footnotetext{
${ }^{16}$ Abraham and Shimer (2001) show that this was due to the dramatic decline in women's transition rate from Employment to Nonparticipation (i.e., to women becoming more attached to the labor force).

${ }^{17} \mathrm{~A}$ higher job finding rate out of unemployment raises the labor force participation rate, because it raises the number of employed workers relative to the number of unemployed workers, and because employed workers are much less likely to leave the labor force than unemployed workers.

${ }^{18}$ These effects can be seen in the bottom panel of Figure 9 for the UE rate (the high UE rate pushed up the participation rate through the "Transitions out of $U ")$, and in the second panel of Figure 9 for the NE rate (the high NE rate pushed up the participation rate through the "Transitions out of E" over 97-99). See Figures 7 and 8 in the appendix for time series of the UE and NE rates.
} 
of $N$ ). Such an assumption is valid if a large event substantially changed the behavior of some nonparticipants. We will refer to this scenario as the "average change" scenario.

However, an alternative scenario could be that the increase in the share of "not want a job" was due to individuals at the margin between "want a job" and "not want a job". If this were the case, the true change in behavior would have been marginal, and a change in the share of "want a job" nonparticipants would have had a negligible effect on the transition rates out Nonparticipation, so that our decomposition would strongly overestimate the contribution of the decline in desire to work to unemployment and participation. We will refer to this scenario as the "marginal change" scenario.

Although it is difficult to definitely conclude in favor of either scenario, we will argue that the "average change" scenario is the more likely one.

First, as previously shown in Figure 10, the transition rate from Nonparticipation to Unemployment displayed a strong downward trend in the 90s, and that trend does line up well with the decline in the share of "want a job". ${ }^{19}$ Moreover, our estimated effect of the decline in the share of "want a job" on transitions out of $\mathrm{N}$ matches well with the observed trend in the "Transition out of N" component of unemployment (figure 7, second panel), suggesting that we are not attributing an unreasonable weight to that mechanism.

Second, if our story is correct and variations in the share of "want a job" have a sizable effect on unemployment, a group without a decline in the share of "want a job" nonparticipants should have had a markedly smaller downward trend in its unemployment rate.

Figure 11 shows that such a differential behavior did occur in the data: while the fraction of "want a job" nonparticipants declined for individuals not living alone, it was roughly flat for individuals living alone. Thus, if our previous result that a lower share of "want a job" nonparticipants leads to a lower unemployment rate is correct, we should observe diverging trends in the unemployment rates of the two groups.

Figure 12 shows that this is indeed the case. In the top panel, we can see that individuals living alone experienced a smaller secular decline in unemployment than individuals not living alone. $^{20}$ To better make this point, the middle panel plots the evolution over time of the difference in (i) unemployment, and (ii) the share of "want a job", for individuals respectively

\footnotetext{
${ }^{19}$ In contrast, the "marginal change" scenario would imply that the change in the share of "want a job" only had a marginal effect on the aggregate transition rate from $N$ to $U$. Thus, the "marginal change" scenario cannot account for the secular decline in the transition rate from $N$ to $U$, unless the transition rates from $N^{w}$ to $U$ and/or from $N^{n}$ to $U$ themselves displayed strong secular declines. However, there were no such declines (Figure 8 in the Appendix).

${ }^{20}$ Similarly, while the participation of individuals not living alone started declining in the early 2000s, the participation rate of individuals living alone kept increasing up until the beginning of the Great Recession. This is again consistent with the smaller decline in desire to work for individuals living alone and consistent with our previous result that a lower desire for work should lead to a lower participation rate.
} 
alone and not alone. That is, we plot $u_{t}^{a}-u_{t}^{n}$ and $m_{t}^{a}-m_{t}^{u}$ where $u_{t}^{a}$ is the unemployment rate of people living alone, $m_{t}^{a}$ the share of "want a job" for people living alone, and with similar definitions for $u_{t}^{n}$ and $m_{t}^{n}$ for people not living alone. We can see a very high correlation between the two series, which is again consistent with our results that the share of "want a job" affects the behavior of the unemployment rate.

A final, more speculative, element that we think can support our "average change" scenario is that of a big shock. If a large shock affected nonparticipants, it could have led them to substantially modify their behavior (e.g., by switching from behaving like an average $N^{w}$ to behaving like an average $N^{n}$ ), and thereby led to large effects on the unemployment and participation rates. In the next section, we explore the reasons for the decline in the share of "want a job" nonparticipants in the second half of the 90s, and we find that a change in the provision of welfare and social insurance, likely linked to the mid-90s welfare reforms and thus arguably a large shock, does account for much of the decline in desire to work.

\section{$5 \quad$ Why fewer people want a job?}

In the second part of the paper, we investigate the reasons for the decline in the share of "want a job" nonparticipants since the mid-90s.

As a preliminary step, we note that the decline in desire to work is concentrated among (i) non-single and (ii) low-income households. While we already saw that the fraction of "want a job" nonparticipants did not decline for those living alone (figure 11), among non-single households, the decline in desire to work is concentrated among low income families (Figure 13). And among low-income non-single households, the decline in desire to work is more pronounced for individuals with children than without (Figure 14).

Since the family structure seems to play an important role, the next section discusses a very simple model of family labor supply to help frame the discussion and guide the empirical analysis. Then, we estimate an empirical model of nonparticipants' propensity to want a job, in which desire to work can depend on individual characteristics, the family structure, as well as the different sources of income. Since the decline in desire to work is a low-income phenomenon, we pay special attention to the role played by welfare income and other social transfer programs.

Our estimates suggest that the mid-90s welfare reforms may have played an important role, and we try to identify their causal effects on desire to work by using a difference-in-difference strategy. We conclude by discussing the implications of our results. 


\subsection{A model of family labor supply}

We sketch a simple framework of family labor supply. ${ }^{21}$ We focus only on family members decision to search for a job, ${ }^{22}$ and we consider a sequential multiple-earner model in which the primary earner makes his/her work decision independently of the secondary earners. The first secondary earner, say the spouse, then makes his/her labor supply decision by maximizing utility, taking account of the primary earner's income. The next secondary earner, say a teenager living in the household, then makes his/her labor supply decision in a similar fashion. And so on, for the other family members.

We posit that there exist search frictions, so that each worker must search in order to get a job, and a worker can increase his/her job finding probability by increasing the intensity of search. ${ }^{23}$

In this framework, we interpret the nonemployment states -Nonparticipant who does not want a job $\left(N^{n}\right)$, Nonparticipant who wants a job $\left(N^{w}\right)$ and Unemployed $(U)$ - as arbitrary distinctions introduced by the household survey and its imperfect measurement of search intensity. Specifically, while search intensity $s$ is a continuous variable, a survey cannot precisely measure $s$. Instead, a household survey like the CPS can classify workers into different labor market states -Nonparticipant who does not want a job $\left(N^{n}\right)$, Nonparticipant who wants a job $\left(N^{w}\right)$ and Unemployed $(U)$ - that correspond to increasing intensities of search.

In this framework, it is easy to show that search intensity (or the propensity to report "want a job") is influenced by the following mechanisms:

1. Returns to employment:

Higher employment income increases desire to work among primary workers, but has an ambiguous effect on desire to work among secondary workers. The effect is ambiguous, because the direct effect is compensated by an added-worker effect (Lundberg, 1985, Juhn and Potter, 2007): As the family income generated by "higher-order" workers increases through higher employment income, desire to work amongst secondary workers decline.

2. Returns to nonparticipation:

Higher nonparticipation income lowers desire to work among primary workers and has an ambiguous effect on desire to work among secondary workers. The ambiguity occurs

\footnotetext{
${ }^{21}$ We leave a more formal labor supply model with intrafamilial choice for the Appendix.

${ }^{22}$ In particular, the model will not fully capture the complex dynamics associated with the movements inand-out of the labor force emphasized in Sections 3 and 4 . This aspect of the problem is a very active area of research. See for instance Krusell et al. (2012).

${ }^{23}$ The model takes the wage and job finding rate as given. Such a simple model could be consistent with nonclearing labor market models, such as search and matching models (Mortensen and Pissarides, 1994), efficiency wage models, or search models with job rationing (Michaillat, 2011).
} 
again because of the added-worker effect, although this time it is because higher returns to nonparticipation lowers search intensity of higher order workers, which lowers disposable income.

3. Heterogeneous preferences:

If the disutility of search varies with demographic characteristics such as age, gender or education, search intensity will vary with demographic characteristics, and a change in the composition of the population will affect the observed average desire to work. ${ }^{24}$

4. Higher asset income lowers search intensity through a "wealth effect".

\subsection{An empirical model of nonparticipants' propensity to want a job}

To quantitatively assess different explanations for the decline in desire to work, we consider a linear model of nonparticipants' propensity to want a job: The probability that a nonparticipant of type $i$ wants a job (i.e., be $N^{w}$ ) at time $t$ is given by

$$
P\left(N^{w} \mid N\right)_{i t}=\beta X_{i t}+\sum_{j=1}^{J} \alpha_{j} w_{j, i t}+\delta_{t}+\varepsilon_{i t}
$$

with $X_{i t}$ a vector of characteristics for type $i$ at time $t, w_{j, i t}$ an income source of type $j$, and $\delta_{t}$ a time dummy. Because we use time fixed effects, our coefficient estimates will depend on cross sectional variation.

To measure worker characteristics as well as income and its different categories, we use matched annual data from the (March) Annual Social and Economic Supplement of the CPS over 1988-2010. In addition to information contained in the basic CPS files, the March supplement includes detailed information on income. Since the March supplement only contains information related to past year's income, we match the March supplements across successive years, so that we can study the relation between the current year's income and desire to work. ${ }^{25}$ Matching March supplements also allows us to instrument for income in year $t$ with income in year $t-1$. There is likely substantial measurement error in the reported income variables, and instrumenting with lagged income variables allows us to correct for the downward bias

\footnotetext{
${ }^{24}$ Another possibility that we will not consider explicitly here is that desire to work changed over time because of a change in preferences. While we do not discard this possibility, we prefer to keep it as a residual explanation.

${ }^{25}$ To construct our data set we link individuals and families across consecutive March supplements. The time series and cross sectional behavior of the want job variable in our matched data set is quite similar to that in the unmatched March supplements and to that in the basic monthly CPS. Because unique individual and family-level identifiers comparable to identifiers in other years are missing in the 1995 March supplement, our data set excludes the years 1994 and 1995, but otherwise includes all years from 1988 to 2010. Since some of the detailed income categories we use were not available on a consistent basis prior to 1988, our sample period starts in 1988.
} 
imparted by this measurement error (under the assumption that the measurement error is i.i.d.).

An individual of type $i$ is defined by the following demographic characteristics: (i) age group -we classify workers into 8 groups spanning 16-85-, (ii) sex, (iii) education level -less than high school, high school or some college, college or more-, (iv) married or not, (v) school status -in school or not-, (iv) position in household -head, spouse, child, other-, and finally (vii) number of children (younger than 19) in the household. $X_{i t}$ is a thus vector of 7 dummy variables.

We consider the different income categories: individual social insurance transfers, individual welfare income, other individual income, asset income, total tax payment, earned family income and family income from social transfers. ${ }^{26}$ Social insurance transfers include supplemental security income (SSI), social security disability insurance (SSDI), social security pensions, survivor's insurance, workmen's compensation and veterans' benefits, ${ }^{27}$ but since we are restricting our sample to individuals younger than 55, the "social insurance transfers" category captures mostly disability insurance. Note that we treat separately individual income, which would affect desire to work through changes in the returns to nonparticipation or employment, and the income provided by higher-order family members (labeled "family income"), which would affect desire to work through added-worker effects. ${ }^{28}$ We also add asset income to capture a possible wealth effect. Income values are deflated using the BEA deflator for personal consumption expenditures.

Finally, since the impairment associated with the receipt of disability insurance is conditioned on the existence of an impairment that (in theory) precludes any work activity (and thus affects desire to work), we include a dummy for receiving disability insurance (SSI or SSDI). Similarly, since welfare recipients are strongly encouraged or mandated to return to employment, participation in a welfare program may affect search intensity and desire to work, we include a dummy for receiving welfare income.

\footnotetext{
${ }^{26}$ Earned labor income includes wages and salaries, self employed income, farm income. Welfare income (also called public assistance) includes AFDC/TANF benefits. Asset income includes interest income, dividend income and rents. The category "other" includes all other individual income sources reported.

${ }^{27}$ SSDI provides income supplements to people who are physically restricted in their ability to be employed because of a notable disability, usually a physical disability. SSI provides stipends to low-income people who are either aged (65 or older), blind, or disabled. There are two important differences between SSI and SSDI: (i) SSI is means-tested, while SSDI is not, and (ii) SSDI is only available to individuals with sufficient recent work experience.

${ }^{28}$ To "rank" family members, we proceed as follows. We classify as primary earner, the family member with the highest earned labor income, or if none, the household head. The second worker is the spouse (if any) or the individual who is closest in age to the primary earner. We continue by considering family members with increasing distance in age from the primary earner.
} 


\subsection{Coefficient estimates}

Table 2 presents our coefficient estimates for the different income categories, and the first column of Table 2 reports coefficient estimates for all individuals aged 16 to $55 .^{29}$

Most strikingly, receiving welfare and receiving disability insurance have very different implications for desire to work. While receiving disability insurance substantially reduces the probability to want to work by 17 percentage points (ppt), consistent with the fact that an impairment should preclude any work activity and thus lower desire to work, receiving welfare increases the probability to want to work by $17 \mathrm{ppt}$. This latter result is consistent with the fact that welfare recipients are strongly encouraged (especially since 1988) to return to employment quickly, which should push welfare recipients to exert more search effort. ${ }^{30}$

Increasing the income from social insurance reduces desire to work (a $\$ 1000$ increase decreases the probability to want a job by $0.7 \mathrm{ppt}$ ), but the effect is small compared to the effect of participation (e.g., being officially recognized as disabled).

Increasing welfare income has no significant effect on desire to work. This small effect is again in contrast with the strong effect of participation (i.e., being on welfare). Thus, most of the effect of the welfare or social insurance programs on desire to work occurs through the program participation margin, as captured by our dummy variables.

Turning to income from higher-order family members, the coefficients for earnings and transfer are highly significant and negative, indicating that an added-worker effect is at play. Specifically, a $\$ 1000$ extra annual family income reduces the probability to want a job by 4.5 ppt for earnings and by about $2 \mathrm{ppt}$ for transfer income. Higher asset income lowers desire to work, consistent with the existence of a wealth effect, although the coefficient is not significant, and lower taxes lower desire to work, indicating again an added-worker effect.

Finally, for demographic characteristics, individuals with the highest expected lifetime return from work are the most likely to want to work: young, highly educated, men are the most likely to want to work. ${ }^{31}$ Being married lowers desire for work, as well as being in school.

Digging deeper into sub-groups, Table 2 also presents the coefficient estimates for prime-age females and individuals younger than 25. Overall, the results are similar and consistent with our aggregate regression.

\footnotetext{
${ }^{29}$ The coefficients were estimated using cross-sectional variation over 1988-2010. Using cross-sectional variation over the pre-1994 period only gives similar results.

${ }^{30}$ In 1988, the Job Opportunity program was created and required a much larger number of welfare recipients to engage in work-related activities (Moffitt, 2003). The legislation also strongly encouraged states to conduct human capital, education, and training programs meant to facilitate return to employment.

${ }^{31}$ The coefficient estimates for demographic characteristics are shown in the Appendix.
} 


\subsection{The welfare reform and wage gains of the 90s}

Before discussing the predictions of the model, it is helpful to briefly discuss two changes in the returns to employment and nonparticipation during the 90s that were of particular relevance for low-income non-single households, the group most affected by the decline in desire to work: (i) the provision of "welfare" was dramatically re-organized in the mid-90s, (ii) real wages increased strongly across the income distribution, propped up by a booming economy.

\subsubsection{The welfare reforms of the mid-90s}

A major re-organization of the provision of welfare took place in the mid-90s with the aim to "end welfare as we know it" (Clinton, 1996) and to move welfare recipients into work.

First, traditional welfare was dramatically re-organized by the Personal Responsibility and Work Opportunity Reconciliation Act of 1996. The Aid to Families with Dependent Children (AFDC) program, a federal assistance program that provided financial assistance to low-income families with children (see Moffitt, 2003 for a detailed review of the program), was replaced by the stricter (in terms of eligibility and time limits) Temporary Assistance for Needy Families program (TANF). With TANF the duration of benefits is limited to five years and the emphasis on return to work is strengthened with sanctions for non-complying applicants (Moffitt, 2003). Following the reform, the number of welfare caseloads declined massively (Blank, 2002) as well as federal spending devoted to AFDC/TANF (Figure 15). ${ }^{32}$

Second, the Earned-Income Tax Credit (EITC) program, a program aimed at offsetting the social security payroll tax for low-income families with children, was expanded in order to encourage work effort (Rothstein and Nichols, 2014). Figure 15 shows the dramatic changes in the organization of "welfare" that took place in the 90s, as a large increase in federal spending devoted to EITC compensated the decline in AFDC/TANF spending.

Note that both the AFDC/TANF program and the EITC program are targeted at individuals who are (i) low income and (ii) with children, which are precisely the individuals affected by the decline in desire to work.

\subsubsection{Strong wage growth over 1995-2000}

The second half of the 90s also coincides with strong positive growth in real wages for all deciles of the income distribution. ${ }^{33}$

\footnotetext{
${ }^{32}$ One can note an interesting correlation between federal spending devoted to AFDC/TANF and the share of "want a job" nonparticipants: both increased in the early 70 s and then decreased markedly over the second-half of the 90s.

${ }^{33}$ Figure 4 in the appendix shows the cumulative changes in real wages since 1994 for different percentiles of the wage distribution.
} 
Since higher wage leads to higher search intensity of primary workers, strong wage growth is unlikely to explain the decline in desire to work through its effect on primary earners. However, large gains in wage income imply large gains in real family income, which can, through the added-worker effect, lead to lower desire to work among secondary workers.

A mechanism going through an added-worker effect is consistent with our earlier observation that desire to work only declined among non-single households (for which an added-worker effect is active).

\subsection{Predicted changes in desire to work}

With the estimated coefficients in hand, we can isolate the contribution of a given characteristic or income variable to the change in the share of "want a job" nonparticipants. Specifically, the contribution of characteristic $x_{i}$ to the decline in desire to work between 1994 and 2006 is given by: ${ }^{34}$

$$
m_{06}-m_{94}=\beta_{i}\left(\bar{x}_{i, 06}-\bar{x}_{i, 94}\right)
$$

with $\bar{x}_{i, t}$ the average value of characteristic $i$ in year $t, \bar{x}_{i, t}=\sum_{i} \varpi_{i t} x_{i t}$ with $\varpi_{i t}$ the share of nonparticipant of type $i$ at time $t$.

The first column of Table 3 shows that, excluding time fixed effects, our model explains about 53 percent of the decline in the fraction of nonparticipants reporting to want a job.

According to our model, the main factors behind the decline in desire to work are changes in welfare benefits and in insurance transfers (mainly disability insurance). Together, they lowered the share of nonparticipants wanting to work by a total of $2.6 \mathrm{ppt}$. Most of this effect is driven by the program participation dummies. As the number of individuals on disability increased, aggregate desire to work declined. And as the number of individuals participating in welfare decreased (Figure 15), aggregate desire to work declined. We return to this point in our discussion section.

Family income and the added-worker effect had a small effect on desire to work because two forces compensated each other. On the one hand, higher family earnings due to higher wages lowered desire to work by $0.5 \mathrm{ppt}$, but on the other hand, lower income from social transfers raised desire to work by $0.3 \mathrm{ppt}$.

Finally, age, sex, education, the fraction of nonparticipants in school, the structure of the household or the number of children do not explain the decline in desire to work.

Looking into sub-groups, the model accounts for respectively 62 and 42 percent of the decline in the share of "want a job" nonparticipants for prime-age women and young workers.

\footnotetext{
${ }^{34}$ We compare 1994 to 2006 in order to avoid cyclical phenomena linked the the Great Recession.
} 
The added-worker effect seems to have played the largest role for young workers, as higher family earnings lowered their desire to work by $0.7 \mathrm{ppt}$.

All in all, our model estimated in the cross-section does a good job at accounting for a large share of the decline in desire to work since 1994, particularly among prime-age female; the largest group affected by the decline in desire to work. While we are still short of explaining all of the decline in desire to work, our approach is likely to be downward biased. The income information in the March CPS is self-reported and thus likely plagued with measurement error. In particular, welfare or social security income, which play la large role in our story, are the income categories with the most measurement error (2010 CPS documentation). We have tried to control for measurement error through IV estimation, but some effects may remain. Relatedly, EITC payments may not be reported by respondents, and the previous analysis may miss the effect of the EITC expansion that could have also contributed to the decline in desire to work (through an added worker effect), a point to which we turn next. ${ }^{35}$

\subsection{Difference-in-difference estimates}

Our previous results suggest that an important factor behind the decline in desire to work is a change in the provision of social transfers. Since welfare reforms of the mid-90s are promising candidates for such changes, this section tries to identify the causal effects of (i) the expansion of EITC and (ii) the AFDC/TANF reform.

To do so, we build on Eissa and Hoynes $(1996,2004)$ and Mc Kernan et al. (2000), and we use a difference-in-difference strategy that exploits the facts that households without children receive little EITC or AFDC/TANF benefits and were little affected by the reforms. First, we identify the effects of the EITC expansion on desire to work by focusing on married individuals, who are eligible to EITC but not to AFDC. Then, we focus on single women with the aim of getting a lower bound on the effect of the AFDC-TANF reform.

\subsubsection{EITC expansion and desire to work among married mothers}

Our first empirical implementation follows Eissa and Hoynes (2004) and focuses on married mothers: Eligibility to EITC depends on the presence of a qualifying child in the family, and we will estimate the effect of the EITC expansion on desire to work by comparing the outcome of the affected group (married women with children) to the outcome of a comparison group that is little affected by the program (married women without children). ${ }^{36}$

\footnotetext{
${ }^{35}$ In theory, EITC payments are parts of social transfers. However, we fear that they are unlikely to be reported as such by respondents, since the transfer-related survey questions never mention receipts of any tax credit.

${ }^{36} \mathrm{~A}$ caveat of this approach is that, while AFDC/TANF is primarily targeted to non-married individuals, a small fraction (about 7\%) of AFDC/TANF caseloads are married couples with children. This is because a
} 
We restrict the sample to married women between 25 and 55. To determine EITC eligibility, we treat as a dependent child any member of the tax-filing unit younger than 19. To better select women that are most likely to receive EITC, the sample is limited to individuals with no level of education higher than a high school degree.

We estimate the following formulation

$$
P\left(N^{w} \mid N\right)_{i t}=\gamma \eta_{g t}+\eta_{g}+\eta_{t}+\beta X_{i t}+\varepsilon_{i t}
$$

where $i, g$, and $t$ index individual, group, and time respectively, and with $X_{i t}$ a vector of controls (age, sex, education, family income, and number of children), $\eta_{g}$ a fixed (group) effect equal to 1 if the woman has a child or more and zero otherwise, $\eta_{t}$ a common time effect equal to 1 for any tax year after 1993, and $\eta_{g t}$ the interaction between fixed group and time effect. Thus, $\gamma$ measures the relative change in desire to work for single women with children after 1993, the year of the EITC expansion. Our estimation period is again 1988-2010.

Table 4 presents the results. After controlling for characteristics, we find that the EITC explains 71 percent of the decline in low-educated married mothers' desire to work between 1988-1993 and 1994-2010.

\subsubsection{AFDC/TANF reform and desire to work among single mothers}

Our second empirical implementation follows Eissa and Hoynes (1996) and Mc Kernan et al. (2000) and focuses on single mothers. To identify the effect of the AFDC/TANF reform on single mothers' desire to work, we compare the outcome of the affected group (single women with children) to the outcome of a comparison group that is unaffected by the program (single women without children) after the reform in 1996.

We use the same specification as with married women, except that the time dummy $\eta_{t}$ equals 1 after 1996, the year of the AFDC/TANF reform. Table 4 presents the results. After controlling for characteristics, our coefficient estimate suggests that the AFDC/TANF reform explains 52 percent of the decline in low-educated single mothers' desire to work between 1988-1995 and 1996-2010.

A caveat is that since single mothers are eligible to both EITC and AFDC/TANF, our difference-in-difference estimate may be contaminated by the EITC expansion, which happened only two years before the AFDC/TANF reform. However, since the EITC expansion should increase desire to work, our estimate can also be seen as a lower bound on the effect of the AFDC/TANF reform on single mothers' desire to work.

program called AFDC-UP provided cash benefits for 2-parent families when the primary earner was unemployed. As a result, our estimate of the effect of EITC may be contaminated by the effect of the AFDC/TANF reform. 


\subsection{Discussion: from welfare to disability?}

Both our cross-sectional estimates (section 5.5) as well as our difference-in-difference estimate (section 5.6) indicate that the AFDC/TANF reform led to a decline in desire to work among nonparticipants. This set of result is surprising in light of a large literature on the effects of the welfare reforms on the labor market. Indeed, it is well accepted that the reform brought many nonparticipants, in particular single mothers, into the labor force (Blank, 2002). However, our findings suggest that the welfare reform lowered desire to work for some nonparticipants, i.e., pushed some nonparticipants away from the labor force.

In this section, we argue that these two views are not necessarily incompatible, and we speculate that the strong work requirements introduced by the AFDC/TANF reform could have, through a kind of "sink or swim" experience, pushed the "stronger" welfare recipients into the labor force and pushed the "weaker" welfare recipients outside of welfare and further away from the labor force, and possibly into disability insurance.

While employment and participation increased for many nonparticipants following the welfare reform, a significant minority of traditional welfare recipients were left both jobless and without welfare support. The decline in the number of caseloads was substantially larger than the corresponding gains in employment: for instance, while employment among single mothers rose by approximately 820,000 between 1995 and 2001, welfare caseloads fell by approximately twice as much (Blank, 2002), suggesting that a number of traditional welfare recipients ended up neither employed nor on welfare. Consistent with this suggestive evidence, welfare leavers' studies (which follow individuals over time after they leave welfare) find that only about 60 percent of welfare leavers are working at some future point (Cancian et al., 1999, Loprest, 2001), and Martinson (2000) finds that 20 percent of leavers never work in a four-year follow-up of work programs.

The emergence of a minority of traditional welfare recipients both jobless and without welfare support could have been caused by the AFDC/TANF reform. The reform made eligibility for welfare much stricter with (i) time limits and (ii) stronger work requirements and the use of sanctions for noncompliant applicants (Blank, 2002). ${ }^{37}$ This made the receipt of welfare strongly conditional on the recipient's ability to find a job. For individuals with poor job finding prospects and strong barriers to employment (e.g., mildly disabled, in poor health,

\footnotetext{
${ }^{37}$ First, adult applicants can only receive benefits for a lifetime maximum of 60 months, and about 20 states chose to impose shorter time limits. Second, according to the Federal provision of TANF, states must require recipients to engage in work activities and must impose sanctions (by reducing or terminating benefits) if an individual does not participate. Half of the families receiving TANF assistance must be engaged in a work activity for at least 30 hours a week (20 for single parents with young children). Job search, job readiness activities, or vocation training can only count as a satisfactory work activity for a limited amount of time.
} 
emotionally disturbed, mentally slow or addicted to drugs or alcohol), ${ }^{38}$ this requirement can be hard to fulfill, leaving them ultimately out of the welfare system and without financial support. ${ }^{39}$

In turn, the need for financial support could have led a number of these traditional welfare recipients to apply for disability insurance, and in particular non-elderly SSI (which provides income support for low-income disabled individuals). A number of papers have argued that there is some degree of substitutability between AFDC/TANF and non-elderly SSI (e.g., Kubik, 1999), and that some of the increase in SSI caseloads can be attributed to the AFDC/TANF reform. ${ }^{40}$ Indeed, both programs serve disadvantaged populations that tend to have low levels of education, minimal work history, and high rates of both physical and mental impairments. Schmidt (2012) even suggests that SSI may be partially playing the role of an alternative safety net in the post-welfare reform era.

However, SSI and AFDC/TANF differ in one important aspect: their emphasis on return to work. While welfare recipients are expected to ultimately return to the labor force, disability recipients are not. In fact, one of the requirements to receive disability benefits is that the "impairment prevents any other work that exists in the national economy" (Daly and Burkhauser, 2003). Thus, our conjecture raises an interesting possibility: While the "welfare to work" reform was designed to do bring welfare recipients into the labor force, the reform could have had the opposite effect on the "weaker" nonparticipants by shifting them from a program with some connection to the labor force (welfare) to a program with no connection to the labor force (disability insurance).

\subsection{A flow decomposition of the share of "want a job" nonparticipants}

To conclude this paper, we show that the worker flows behind the movements in the share of "want a job" nonparticipants are consistent with our "sink or swim" conjecture. Importantly, and although the evidence is tantalizing, we caution that these are just correlations, and we leave a proper study of the "sink or swim" interpretation of the welfare reform for future research. ${ }^{41}$ More details about the decomposition are provided in the Appendix.

\footnotetext{
${ }^{38}$ For instance, Dworsky and Courtney (2007) find that most of the TANF applicants in Milwaukee face such barriers to employment.

${ }^{39}$ Consistent with this idea, Grogger (2000) finds that welfare time limits lowered the number of caseloads by about 200,000 during the second-half of the 90 s.

${ }^{40} \mathrm{Schmidt}$ and Sevak (2004) find that the pre-reform state-level welfare waivers -pre-reform experiments of a welfare system with stronger work requirements- led to a significant increase in the likelihood that single-mother families reported SSI receipt. Schmidt (2012) finds that the TANF sanction policies significantly increased SSI caseloads share for both adults and children. Kubik (2003) also argues that switching from AFDC/TANF to SSI has financial advantages both for the individuals as well as the state.

${ }^{41}$ Note that the point of this paper is to show that time-variation in the characteristics of nonparticipants -the decline in the share of want a job- are a crucial aspect of secular movements in the unemployment and
} 
Using our accounting framework, we can proceed as with the unemployment and participation rates and decompose movements in the share of "want a job" nonparticipants into the separate contributions of the worker flows in and out of $\left\{E, U, N^{w}, N^{n}\right\}$.

We find that two worker flows, the flows between $N^{w}$ and $N^{n}$, account for most of the decline in the fraction of "want a job" nonparticipants $\left(m_{t}\right)$ since the mid-90s. Figure 16 plots the share of "want a job" nonparticipant, $m_{t}$, over 1994-2010 along with a counterfactual $m_{t}$ generated solely by movements in $N^{w} N^{n}$ and $N^{n} N^{w}$ transitions. We can see that the two flows account for most of the downward trend in $m_{t}$ since $1994,{ }^{42}$ so that the lower share of "want a job" is due mainly to (i) lower entry of nonparticipants into "want a job" (lower $N^{n} N^{w}$ ), and (ii) higher exit from "want a job" to "not want a job" (higher $\left.N^{w} N^{n}\right) \cdot{ }^{43}$

The behavior of the $N^{n} N^{w}$ and $N^{w} N^{n}$ flows is consistent with the "sink" aspect of the welfare reform, i.e., the reform would have pushed the weaker nonparticipants further away from the labor force. The lower $N^{n} N^{w}$ rate could be due to lower entry into welfare (recall that an individual on welfare is much more likely to want a job), and the higher $N^{w} N^{n}$ rate could be due to higher exit from welfare (and possibly entry into a disability program).

Interestingly, the flows in and out of "want a job" are also consistent with the "swim" aspect of the welfare, i.e., the reform would have pushed the stronger nonparticipants into the labor force. Although most of the decline in the share of "want a job" between 1994 and 2001 is due to flows between $N^{w}$ and $N^{n}$, the next most important factor (figure 16) is an increase in the flows from "want a job" into the labor force (the flows from $N^{w}$ to $U$ or $E$ ). ${ }^{44}$

\section{Conclusion}

This paper argues that a key aspect of the US labor market is the presence of time-varying heterogeneity across nonparticipants, i.e., changes in the composition of the nonparticipation pool. In particular, we find that the share of nonparticipants who report wanting to work declined over the past 35 years, with a particularly strong decline in the second-half of the 90s. The decline primarily reflected reductions for prime age females, and to a lesser extent, young people.

participation rate. We do not claim that the contribution of the late-90s decline in the share of want a job to (i) unemployment (about -.5 ppt) and (ii) participation (about -1.75 ppt) is the effect of the welfare reform on unemployment and participation. Doing so would require identifying the contribution of the welfare reform to each worker flow (for instance, using a difference-in-difference approach as in the previous section) and then translating the movements in the flows caused by the reform into changes in unemployment and participation rates.

${ }^{42}$ Confirming this visual inspection, a variance decomposition exercise as in Fujita and Ramey (2009) shows that $\lambda_{t}^{N^{w} N^{n}}$ and $\lambda_{t}^{N^{n} N^{w}}$ account for, respectively, $50 \%$ and $25 \%$ of the variance of $m_{t}$.

${ }^{43}$ The transition rates between $N^{w}$ and $N^{n}$ are plotted in figure 9 in the Appendix.

${ }^{44}$ The transition rates from "want a job" $\left(N^{w}\right)$ to U or E are plotted in figure 8 in the appendix. 
A decline in desire to work lowers both participation and unemployment because a nonparticipant who wants to work has both a higher probability of entering the labor force and a higher probability of joining unemployment conditional on entering the labor force. We quantify the effect of the decline in desire to work in the late 90 s on aggregate labor market variables and find that the unemployment rate was lowered by about $0.5 \mathrm{ppt}$ and the participation rate by about 1.75 ppt. Taken together, population aging and lower desire to work can account for the bulk of low-frequency movements in unemployment since the late 60s.

We explore possible explanations for the decline in desire to work among nonparticipants using cross-sectional estimates of a model of nonparticipants' propensity to want a job as well as difference-in-difference estimates of the effects of the mid-90s welfare reforms.

Our findings suggest that the mid-90s "welfare to work" reforms -the 1993 EITC expansion and the 1996 AFDC/TANF reform- played an important role in lowering desire to work among nonparticipants. Our cross-sectional estimates imply that changes in the provision of welfare and social insurance explain about 60 percent of the decline in desire to work among prime-age females, while the difference-in-difference estimates attribute between 50 and 70 percent of the decline in mothers' desire to work to the welfare reforms.

We conjecture that two mechanisms could explain these results. First, the EITC expansion raised family income and reduced secondary earners' (typically women) incentives to work. Second, the strong work requirements introduced by the AFDC/TANF reform would have, through a kind of "sink or swim" experience, left the "weaker" (i.e., least able to find work) welfare recipients without welfare and pushed them away from the labor force and possibly into disability insurance.

Our conjecture raises an interesting possibility: While the "welfare to work" reform was designed to strengthen the incentives to work and to bring welfare recipients into the labor force, the reform could have had the opposite effect on some nonparticipants, either by giving secondary earners less incentives to work, and/or by shifting the "weaker" nonparticipants from a program with some connection to the labor force (welfare) to a program with no connection to the labor force (disability insurance). Exploring this possibility is an important task for future research.

We end this paper by speculating about possible future values for the unemployment rate at the next business cycle peak. As of March 2015, more than five years since the end of the recession (as defined by the NBER), the unemployment rate stands at 5.5 percent. The "long-run" forces that drove the unemployment rate to a 40 year low of 3.8\% in April 2000, -aging and lower desire to work-, are still present today (Figure 6), but are masked by a low job finding rate that is still 20 percent below its pre-recession peak of 2006 and 30 percent below its 2000 peak. Bringing workers' transition rates back to their 2000 levels and holding 
the share of "want a job" nonparticipants at its current level imply an unemployment rate at 3.8 percent. Perhaps more realistically, bringing workers' transition rates back to their 2006 pre-recession levels would imply an unemployment rate of 4.5 percent, suggesting that the unemployment rate still has substantial room for improvement. ${ }^{45}$

\footnotetext{
${ }^{45}$ One can do a similar exercise for the participation rate. Bringing workers' transition rates back to their 2006 levels (but keeping both demographics and the share of "want a job" at their current levels) implies a participation rate of 65.8 percent, lower than the 2000 peak at 67.3 percent, but substantially higher than the rate of 62.7 percent as of March 2015 .
} 


\section{References}

[1] Aaronson, Daniel, Jonathan Davis, and Luojia Hu. 2012. "Explaining the Decline in the U.S. Labor Force Participation Rate." FRB Chicago, Chicago Fed Letter 296 (March).

[2] Autor D., M. Duggan, "The Rise In The Disability Rolls And The Decline In Unemployment," The Quarterly Journal of Economics, vol. 118(1), pp 157-205, 2003.

[3] Barnichon, R. "Vacancy Posting, Job Separation, and Unemployment Fluctuations," Journal of Economic Dynamics and Control, 36(3): 315-330, 2012.

[4] Blanchard O. and P. Diamond. "The Beveridge Curve," Brookings Paper on Economic Activity, 1:1-60, 1989.

[5] Blanchard O. and P. Diamond. "The Cyclical Behavior of the Gross Flows of U.S. Workers," Brookings Papers on Economic Activity, vol. 21(2), 85-156, 1990.

[6] Blank, R. "Evaluating Welfare Reform in the United States," Journal of Economic Literature, 40(4): 1105-1166, 2002.

[7] Bleakley H., A. Ferris, and J. Fuhrer "New Data on Worker Flows during Business Cycles," New England Economic Review, July-August, 1999.

[8] Cancian, M, R.Haveman, T. Kaplan, D. Meyer and B. Wolfe. "Work, Earnings and WellBeing After Welfare," in Economic Conditions and Welfare Reform. Sheldon H. Danziger, ed. Kalamazoo, MI: W.E. Upjohn Institute Employment Res., pp. 161-86, 1999.

[9] Clark, K. and L. Summers. "Labor Market Dynamics and Unemployment: A Reconsideration." Brookings Papers on Economic Activity, (1): 13-60 1979.

[10] Daly M. and R. Burkhauser "The Supplemental Security Income Program," NBER Chapters in: Means-Tested Transfer Programs in the United States, pages 79-140, 2003.

[11] Darby, M. J. Haltiwanger and M. Plant. "The Ins and Outs of Unemployment: The Ins Win," NBER Working Paper, 1986.

[12] Dworsky, A., and M. Courtney. "Barriers to employment among TANF applicants and their consequences for self-sufficiency," Families in Society 88(3): 379-89, 2007.

[13] Eissa, N and J. Liebman. "Labor Supply Response to the Earned Income Tax Credit," The Quarterly Journal of Economics, vol. 111(2), pages 605-37, May 1996. 
[14] Eissa, N and H. Hoynes. "Taxes and The Labor Market Participation of Married Couples: The Earned Income Tax Credit," Journal of Public Economics, vol88, pages 1931-1958, August, 2004.

[15] Elsby, M. B. Hobijn and A. Sahin. "On the Importance of the Participation Margin for Labor Market Fluctuations," Working Paper, 2013.

[16] Elsby, M. R. Michaels and G. Solon. "The Ins and Outs of Cyclical Unemployment," American Economic Journal: Macroeconomics, 2009.

[17] Elsby, M. and M. Shapiro. "Why Does Trend Growth Affect Equilibrium Employment? A New Explanation of an Old Puzzle," American Economic Review, June 2012.

[18] Erceg, C. and A. Levin. "Labor Force Participation and Monetary Policy in the Wake of the Great Recession," Working Paper 2013.

[19] Flaim, P. "The Effect of Demographic Changes on the Nation's Unemployment Rate," Monthly Labor Review, 3-10, 1979.

[20] Flinn, C. and J. Heckman. "Are Unemployment and Out of the Labor Force Behaviorally Distinct Labor Force States?," Journal of Labor Economics, vol. 1(1), pages 28-42, 1983.

[21] Fujita, S. and G. Ramey. "The Cyclicality of Separation and Job Finding Rates," International Economic Review, 2009.

[22] Gordon, R. Inflation, flexible exchange rates, and the natural rate of unemployment. In Workers, Jobs and Inflation, Brookings Institute, 89-152, 1982.

[23] Grogger, J. "The Effect of Time Limits, the EITC, and Other Policy Changes on Welfare Use, Work, and Income Among Female-Headed Families," Review of Economics and Statistics, Vol. 85, No. 2, Pages 394-408, 2003.

[24] Hall, R. "Why is the unemployment rate so high at full employment" Brookings Papers on Economic Activity, 33:369-402, 1970.

[25] Hotchkiss, J., Pitts, M., Rios-Avila, F. 2012. "A Closer Look at Non-Participants during and after the Great Recession." Federal Reserve Bank of Atlanta Working Paper No.201210.

[26] Jones, S. and C. Riddell. "The Measurement of Unemployment: An Empirical Approach," Econometrica, 67, pp 142-167, 1999. 
[27] Juhn, C., K. Murphy, R. Topel. "Current Unemployment, Historically Contemplated." Brookings Papers on Economic Activity, 79-116, 2002.

[28] Juhn, C. and S. Potter "Is There Still an Added-Worker Effect?," NBER Working aper, 2007.

[29] Krusell P., T. Mukoyama, R. Rogerson and A. Sahin. "Is Labor Supply Important for Business Cycles?," NBER Working Papers 17779, 2012.

[30] Kubik, J. "Incentives for the Identification and Treatment of Children with Disabilities: The Supplemental Security Income Program." Journal of Public Economics 73(2): 187$215,1999$.

[31] Kubik, J. "Fiscal Federalism and Welfare Policy: The Role of States in the Growth of Child SSI." National Tax Journal 56(1): 61-79, 2003.

[32] Loprest, P."How Are Families that Left Welfare Doing? A Comparison of Early and Recent Welfare Leavers" FRBNY Economic Policy Review, 2001.

[33] Lundberg, S. "The Added Worker Effect", Journal of Labor Economics, 3(1), 11-37, 1985.

[34] Martinson, K. "The National Evaluation of Welfare-to-Work Strategies Evaluation: The Experience of Welfare Recipients Who Find Jobs." MDRC for U.S. Dept. Health Human Services. Washington, DC, 2000.

[35] McKernan, S., R. Lerman, N. Pindus and J. Valente, "The relationship between metropolitan and non-metropolitan locations, changing welfare policies, and the employment of single mothers", Mimeo, 2000.

[36] Moffitt, R. "The Temporary Assistance for Needy Families Program," NBER Chapters, in: Means-Tested Transfer Programs in the United States, pages 291-364, 2003

[37] Nekarda, C. "A Longitudinal Analysis of the Current Population Survey: Assessing the Cyclical Bias of Geographic Mobility". Working Paper, 2009.

[38] Michaillat, P. "Do Matching Frictions Explain Unemployment? Not in Bad Times," American Economic Review, 2011.

[39] Moffitt, R. "The Temporary Assistance for Needy Families Program," NBER Chapters, in: Means-Tested Transfer Programs in the United States, pages 291-364, 2003.

[40] Moffitt, R. ""The U.S. Employment-Population Reversal in the 2000s: Facts and Explanations" Brookings Papers on Economic Activity, 201-264, 2012. 
[41] Perry, G. "Changing Labor Markets and Inflation," Brookings Papers on Economic Activity, 411-441, 1970.

[42] Rothstein, J. and A. Nichols. "The Earned Income Tax Credit," NBER Chapters, in: Means-Tested Transfer Programs, 2014.

[43] Schmidt, L. and P. Sevak. "AFDC, SSI, and Welfare Reform Aggressiveness: Caseload Reductions vs. Caseload Shifting," Journal of Human Resources 39(3): 792-812, 2004.

[44] Shimer, R., "Why is the U.S. Unemployment Rate So Much Lower?" NBER Macroeconomics Annual, 13, pp. 11-61, 1998.

[45] Shimer, R., "The Impact of Young Workers on the Aggregate Labor Market," Quarterly Journal of Economics, 116, 969-1008, 2001.

[46] Shimer, R. "Reassessing the Ins and Outs of Unemployment," Review of Economic Dynamics, vol. 15(2), pages 127-148, April, 2012.

[47] Summers, L. "Why is the Unemployment Rate So Very High near Full Employment," Brookings Papers on Economic Activity, vol. 17(2), pages 339-396., 1986.

[48] Van Zandweghe, W. 2012. "Interpreting the Recent Decline in Labor Force Participation." Economic Review, Federal Reserve Bank of Kansas City, 5-34. 


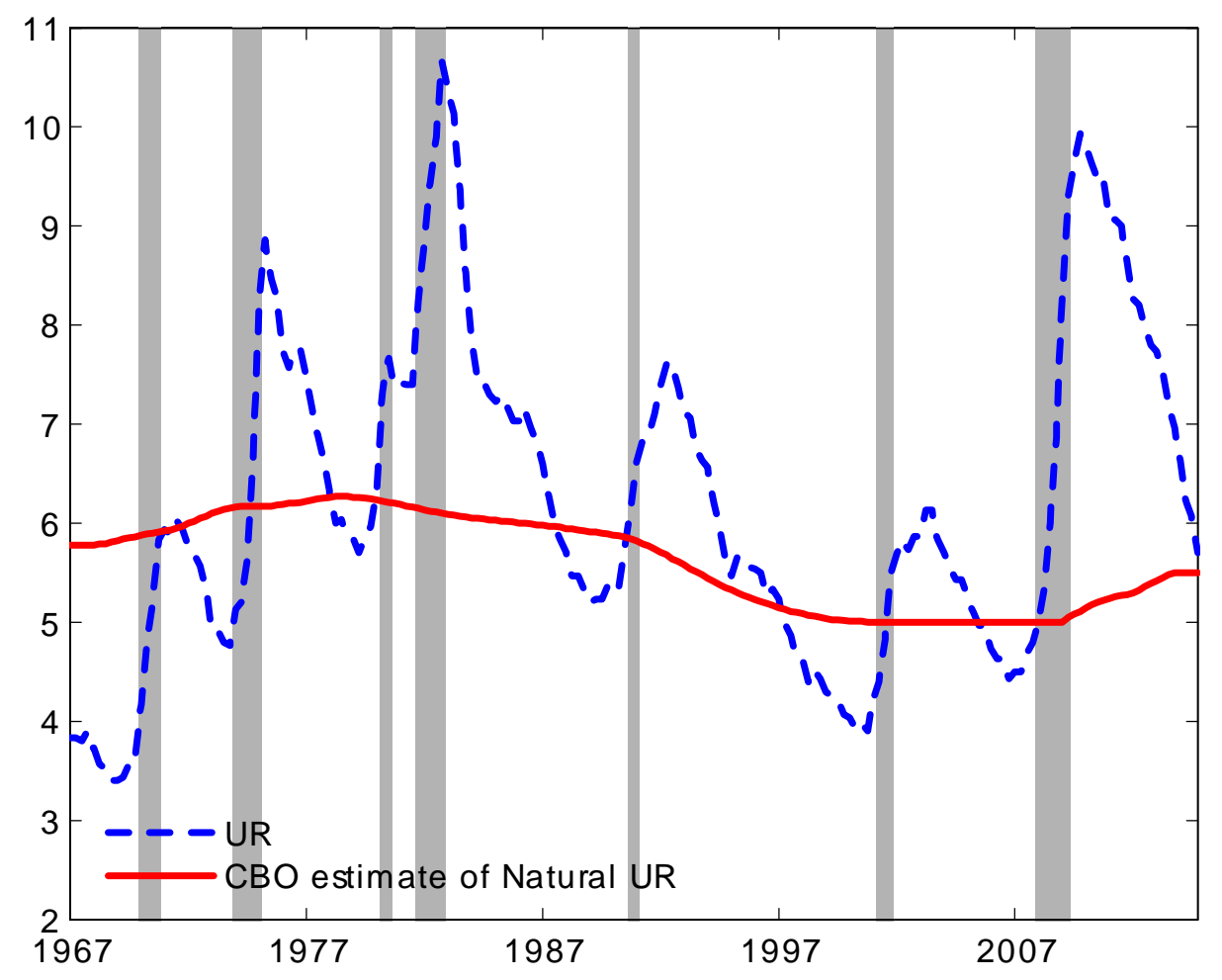

Figure 1: Unemployment rate (UR) and CBO estimate of the natural rate of unemployment, 1967-2014. 


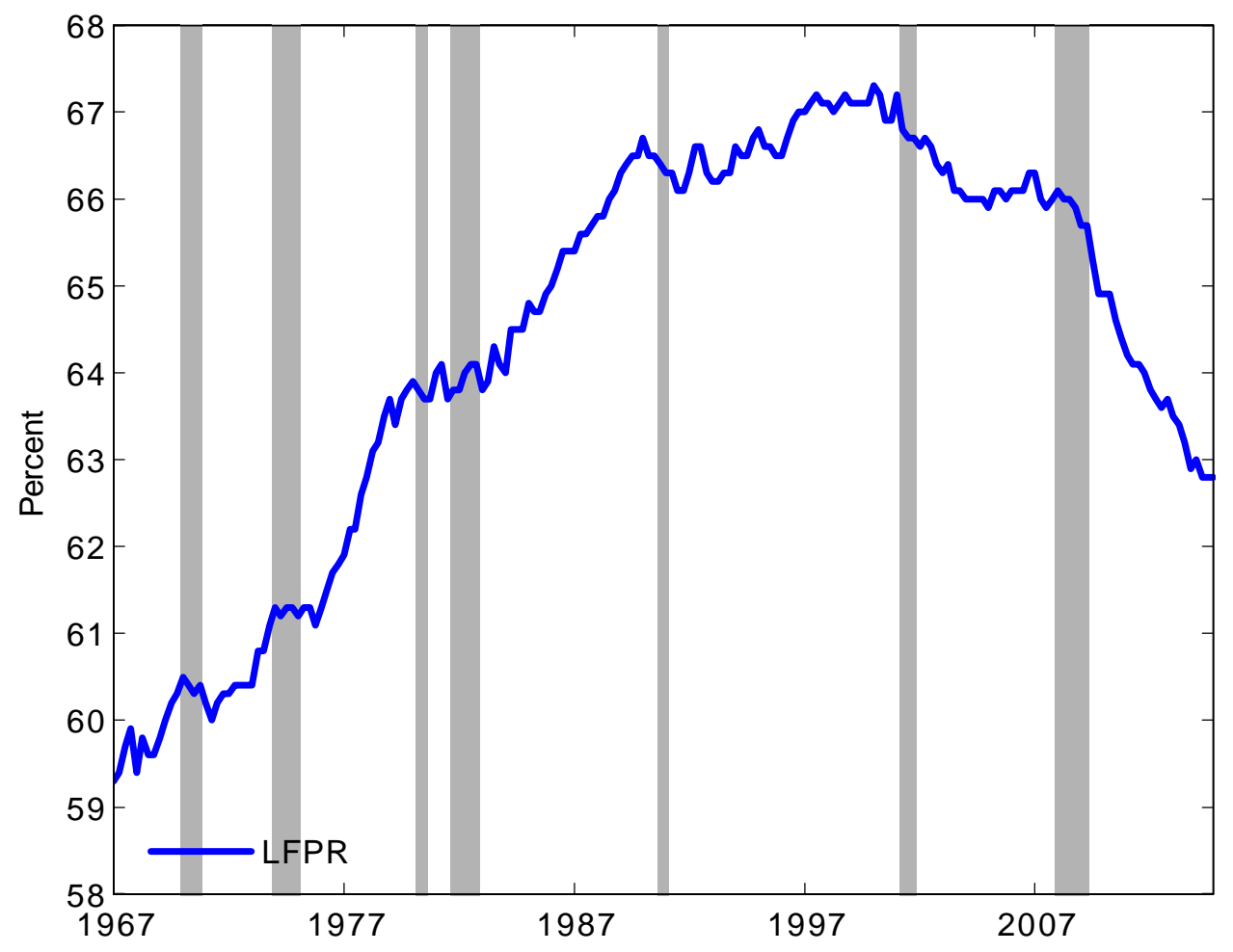

Figure 2: Labor force participation rate (LFPR) and CBO estimate of the potential LFPR, 1967-2014. 


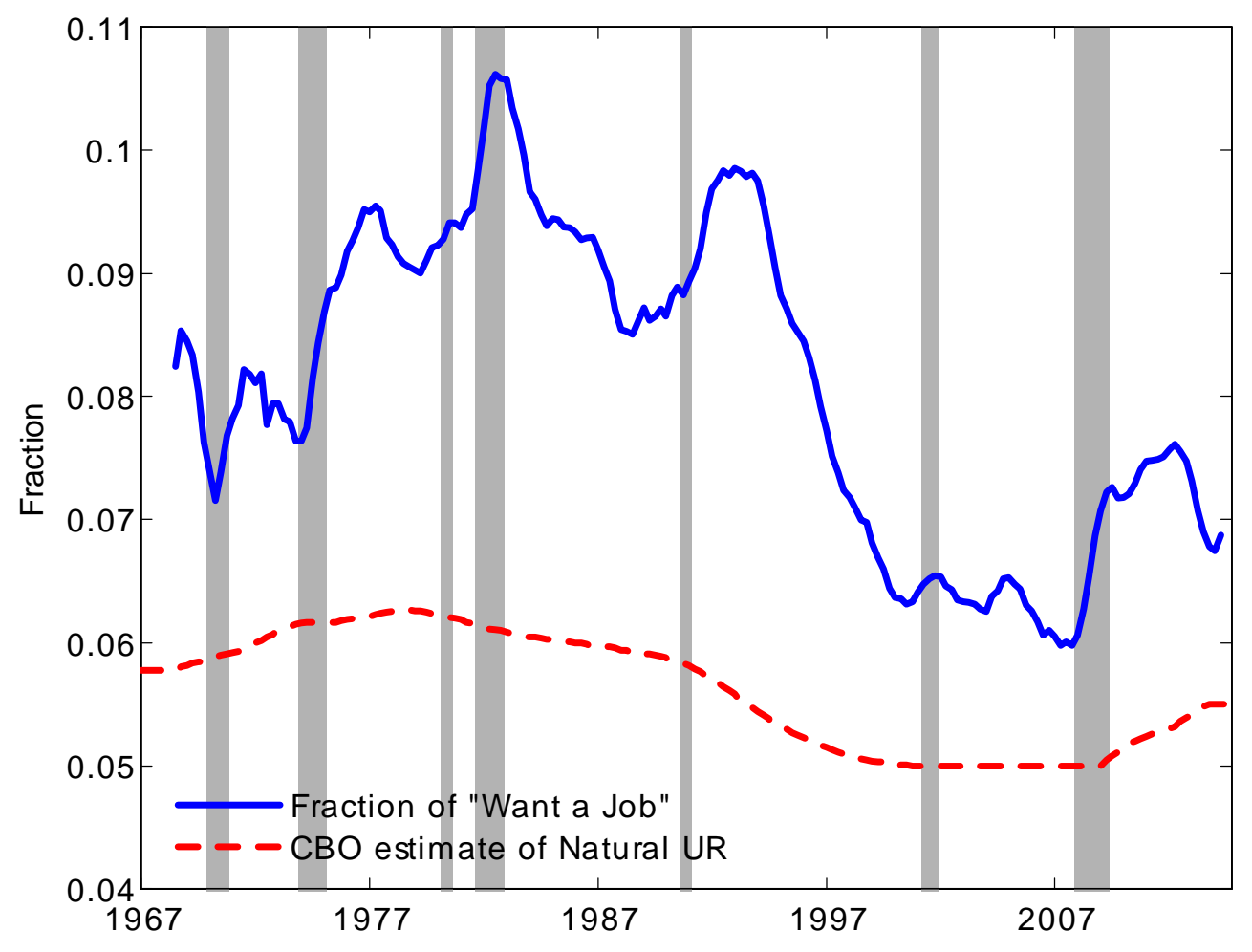

Figure 3: Fraction of nonparticipants who report "wanting a job" (solid line, 4-quarter moving averages) and CBO estimate of natural unemployment rate (dashed line), 1967-2014. 


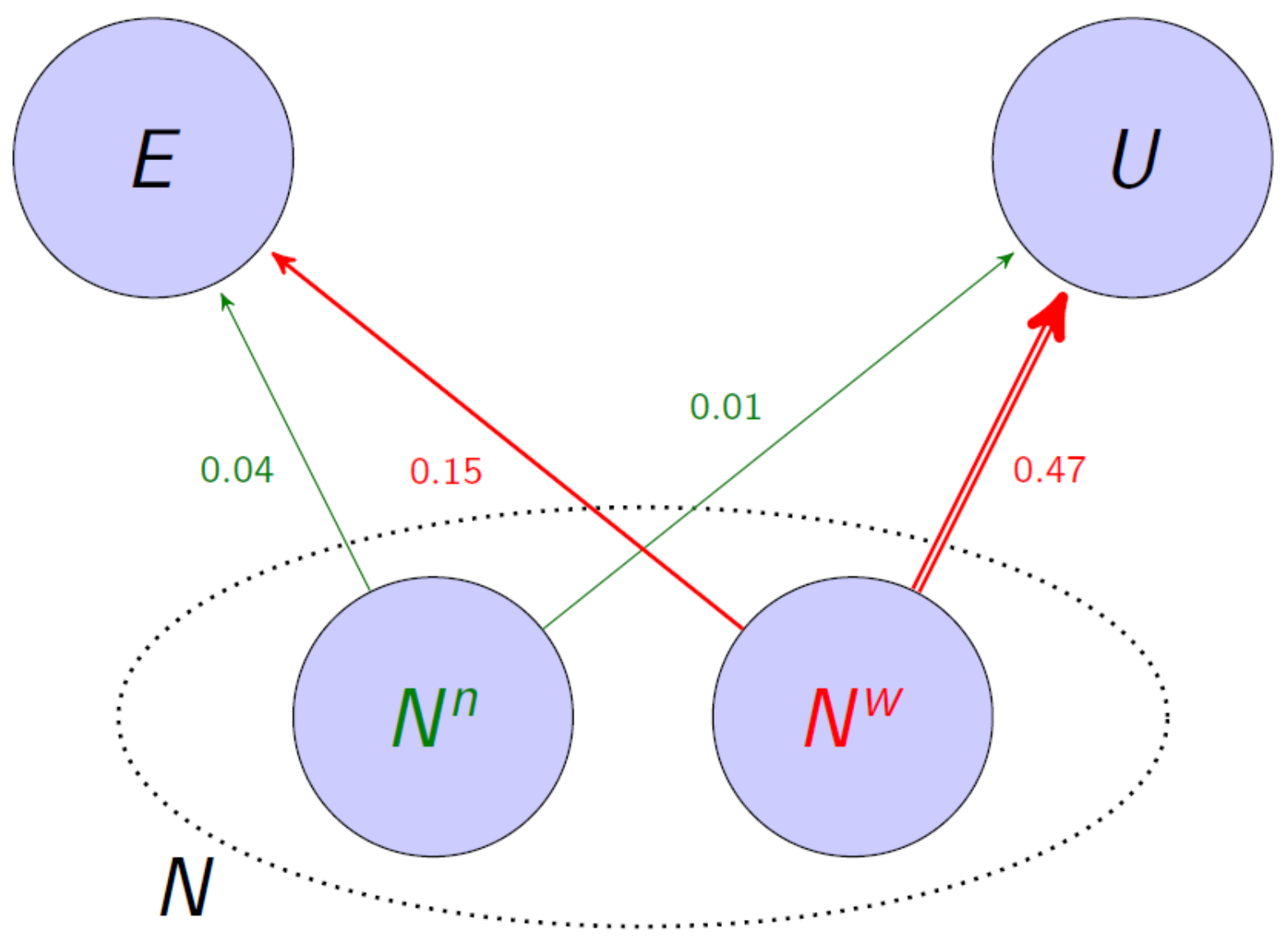

Figure 4: Average monthly transition probabilities out of Nonparticipation for nonparticipants who want a job $\left(N^{w}\right)$ and nonparticipants who do not want a job $\left(N^{n}\right), 1994-2010$. 

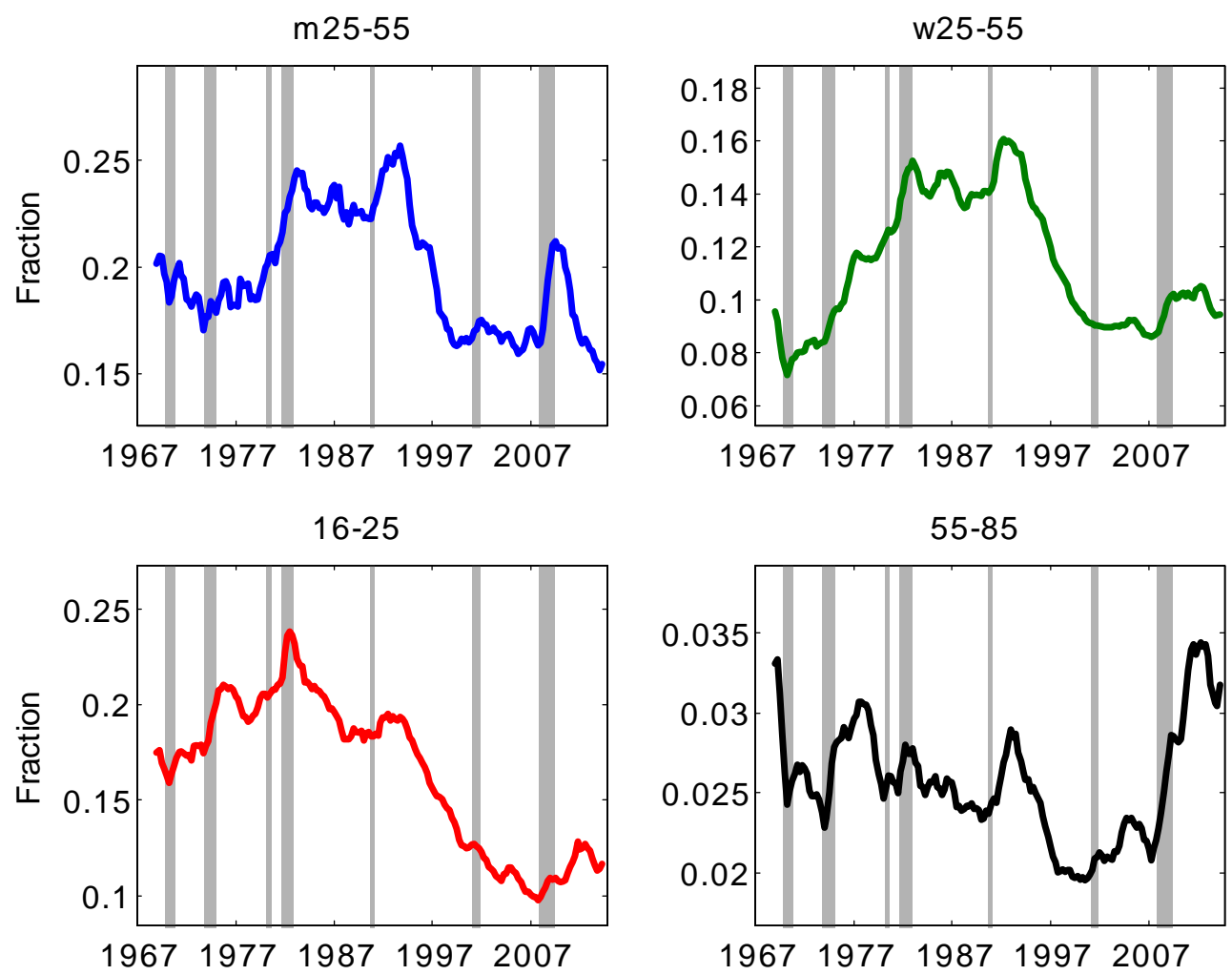

Figure 5: Fraction of nonparticipants who report "wanting a job" by demographic group: male 25-55, female 25-55, younger than 25, and older than 55. 4-quarter moving averages, 1969-2014. 

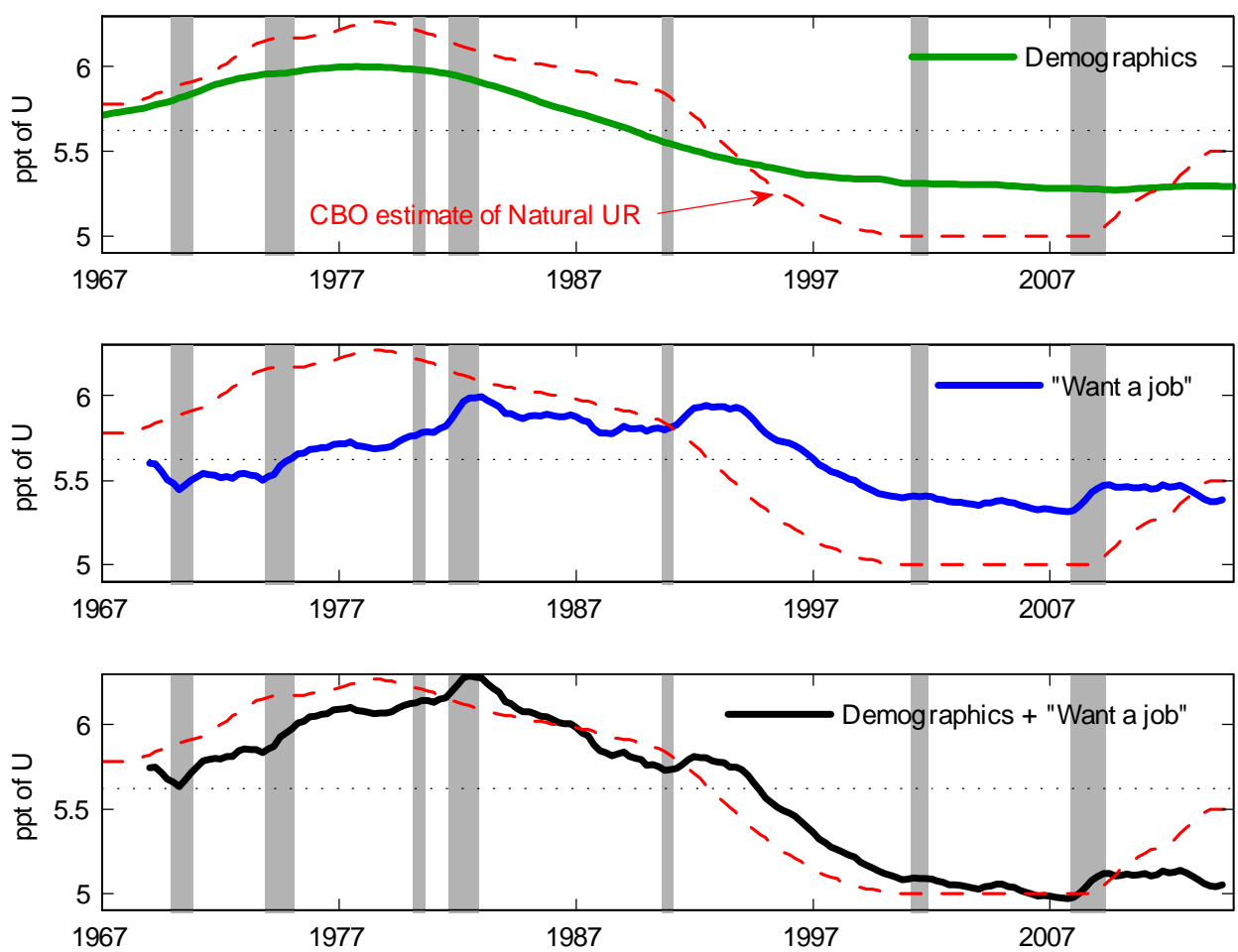

Figure 6: Effects of composition changes on the aggregate unemployment rate (U). Upper panel: effect of demographics. Middle panel: effect of changes in the share of "want a job" nonparticipants. Bottom panel: effect of changes in demographics and the share of "want a job" nonparticipants. The dashed line is the CBO estimate of the natural unemployment rate. For clarity of exposition, the series are level shifted with their mean set to the mean of the CBO natural rate. The plotted series are 4-quarter moving averages. 1967-2014. 

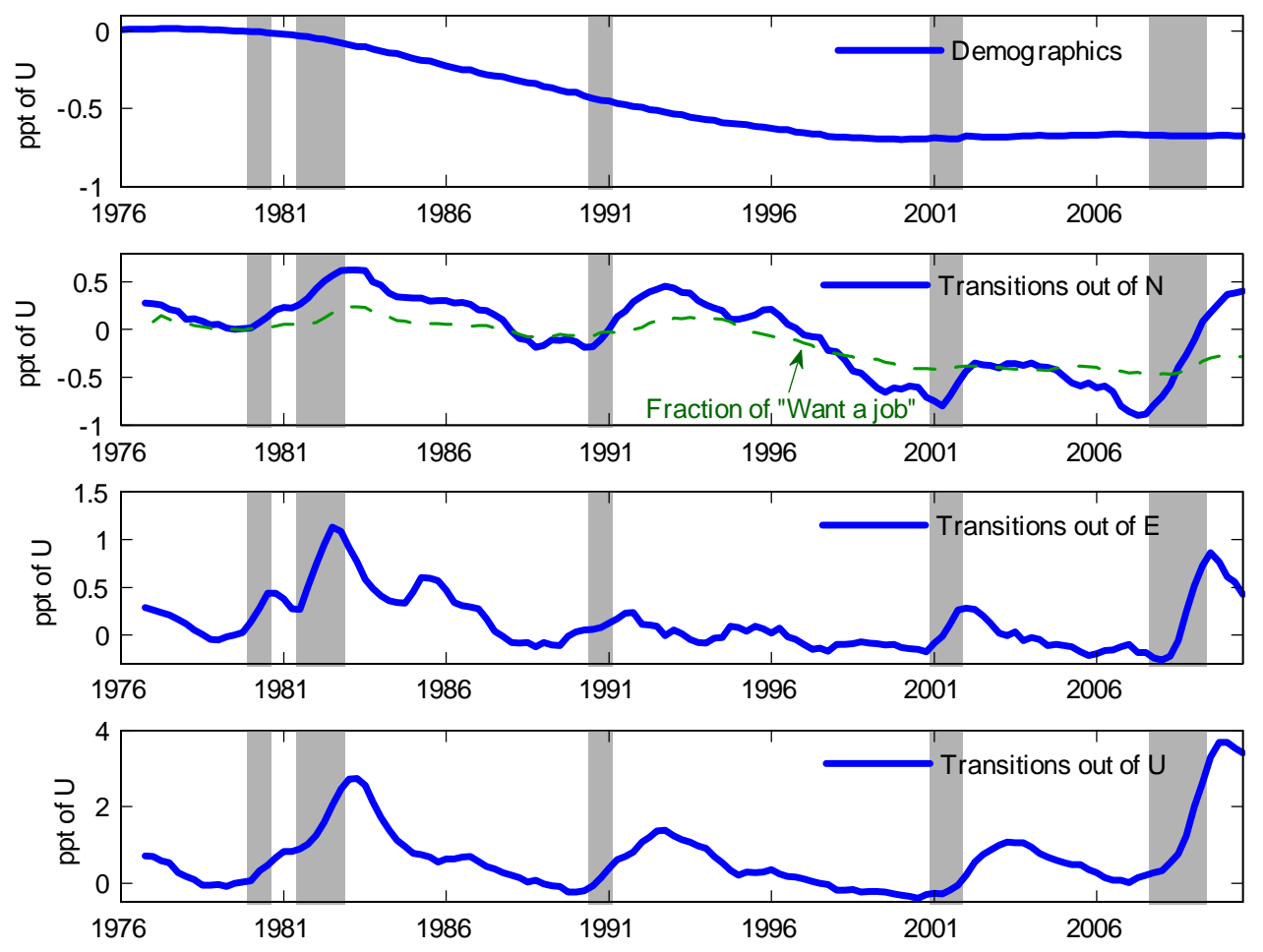

Figure 7: Decomposition of the unemployment rate into the contributions of (i) demographics (top panel), (ii) transition rates out of Nonparticipation - NE and N-U flows- (second panel), (iii) transition rates out of Employment -EN and EU flows- (third panel), and (iv) (iii) transition rates out of Unemployment -UN and UE flows- (bottom panel). Summing up the four components gives the aggregate unemployment rate. The dashed line in the second panel plots the contribution of the share of "want a job" nonparticipants to the unemployment rate. For clarity of exposition, the contribution of each component is set to 0 in 1979Q4. The plotted series are 4-quarter moving averages, 1976-2010. 

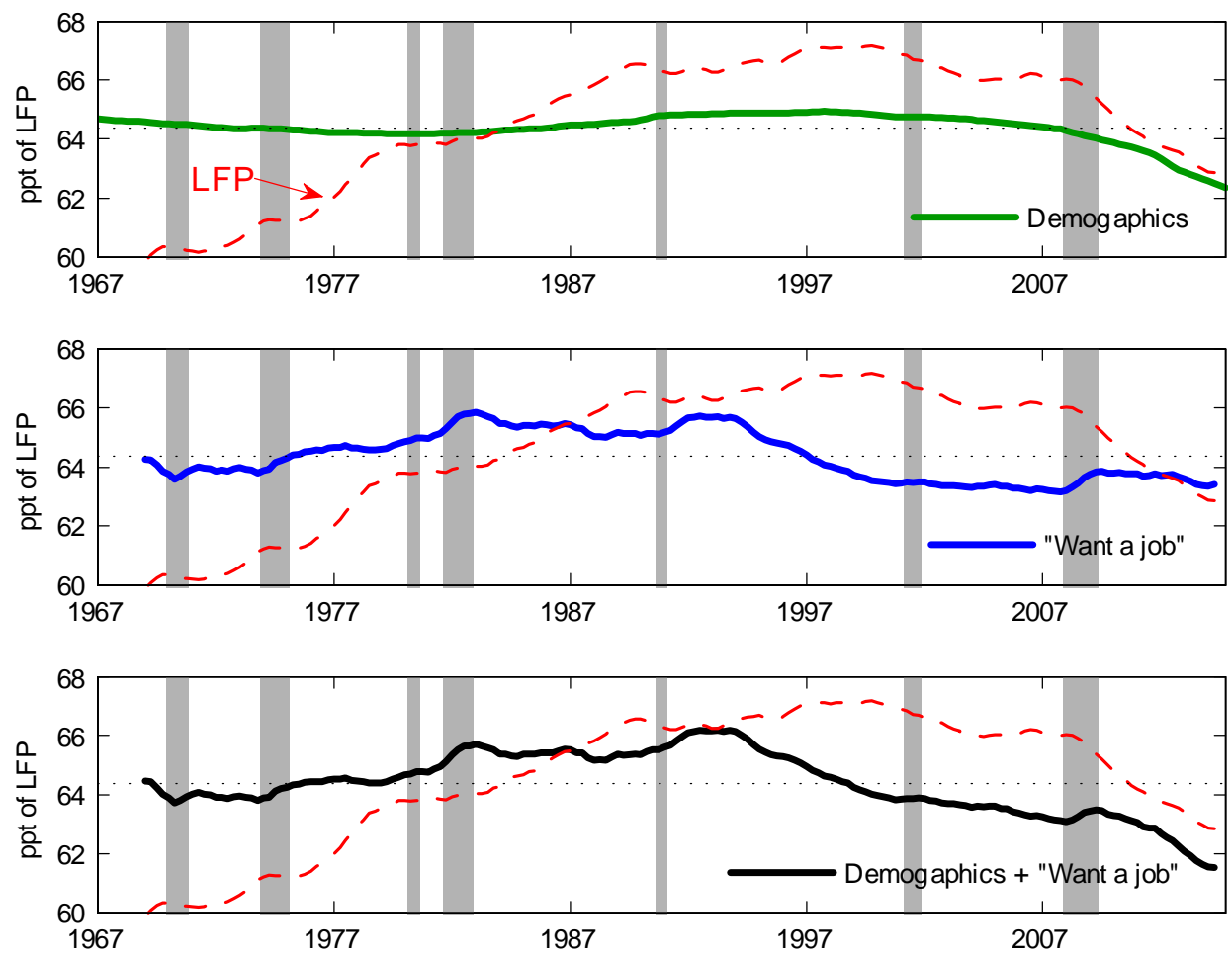

Figure 8: Effects of composition changes on aggregate labor force participation rate (LFP). Upper panel: effect of demographics. Middle panel: effect of changes in the share of "want a job" nonparticipants. Bottom panel: effect of changes in demographics and the share of "want a job" nonparticipants. The dashed line is the actual LFP. For clarity of exposition, the series are level shifted with their mean set to the mean of aggregate LFP. The plotted series are 4-quarter moving averages. 1967-2014. 

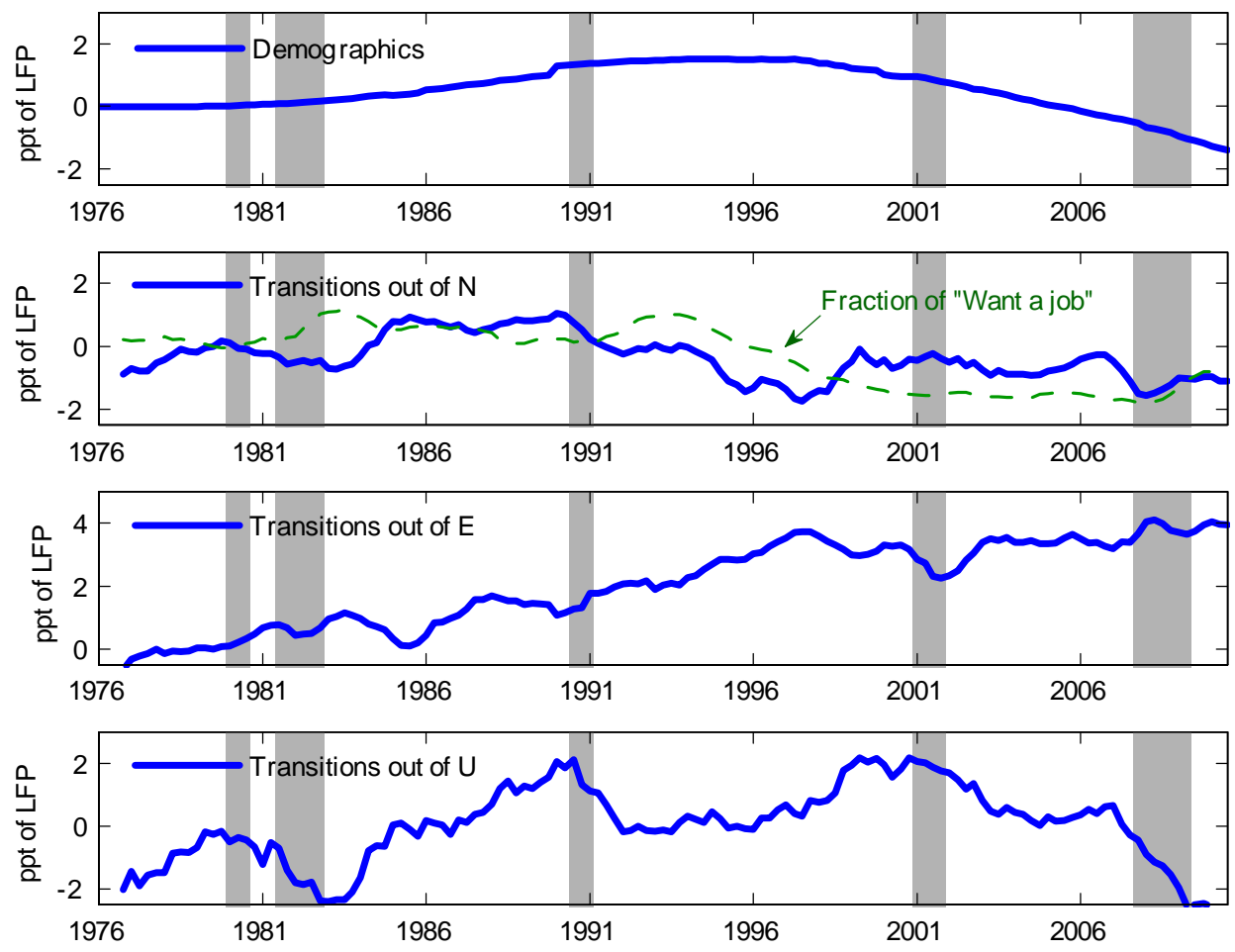

Figure 9: Decomposition of the participation rate into the contributions of (i) demographics (top panel), (ii) transition rates out of Nonparticipation -NE and NU flows- (second panel), (iii) transition rates out of Employment -EN and EU flows- (third panel), and (iv) (iii) transition rates out of Unemployment -UN and UE flows- (bottom panel). Summing up the four components gives the aggregate participation rate. The dashed line in the second panel plots the contribution of the share of "want a job" nonparticipants to the participation rate. For clarity of exposition, the contribution of each component is set to 0 in 1979Q4. The plotted series are 4-quarter moving averages, 1976-2010. 


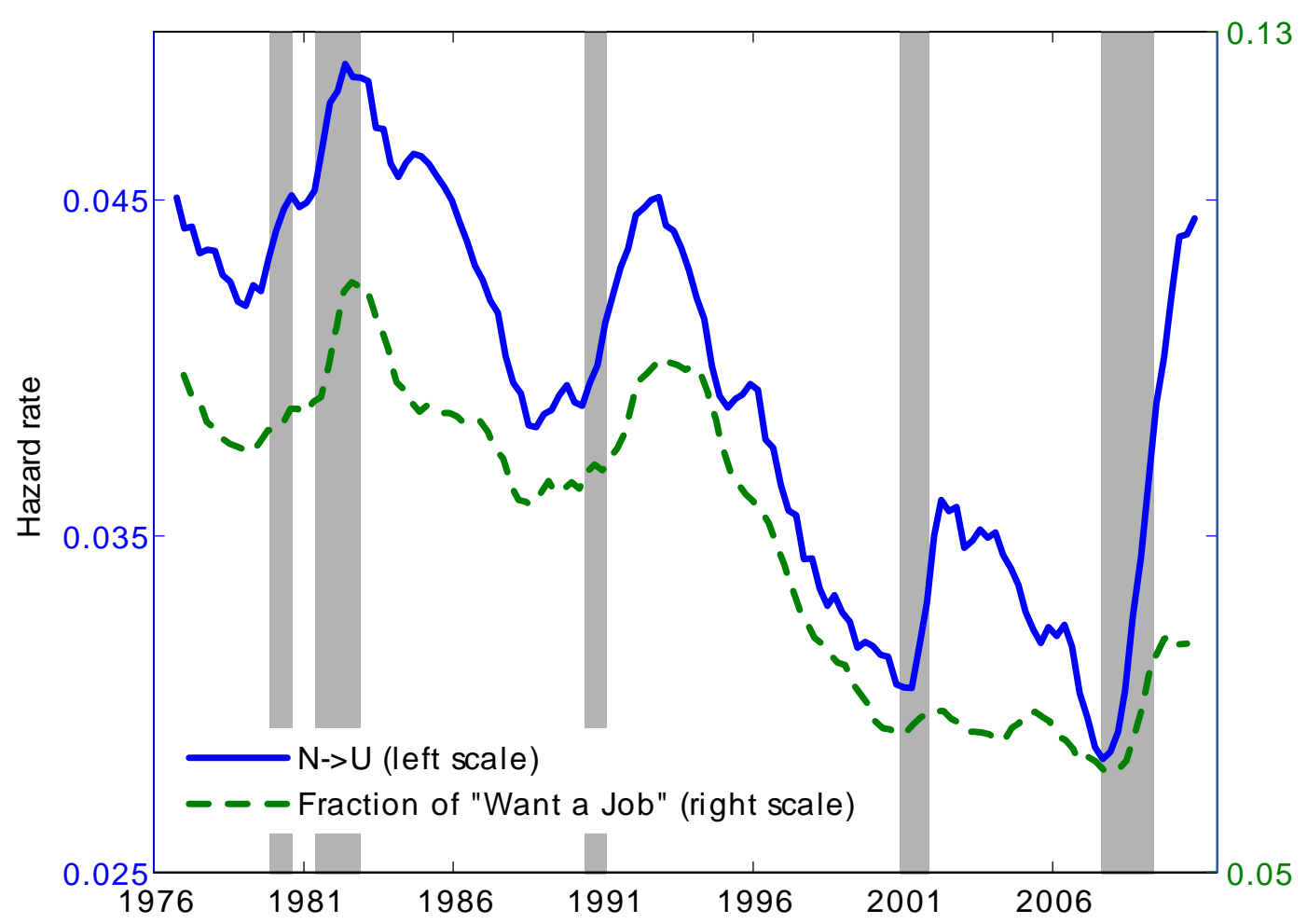

Figure 10: The Nonparticipation to Unemployment transition rate (NU) on the left scale, and the share of "want a job" nonparticipants (right scale). The plotted series are 4-quarter moving averages, 1976-2012. 


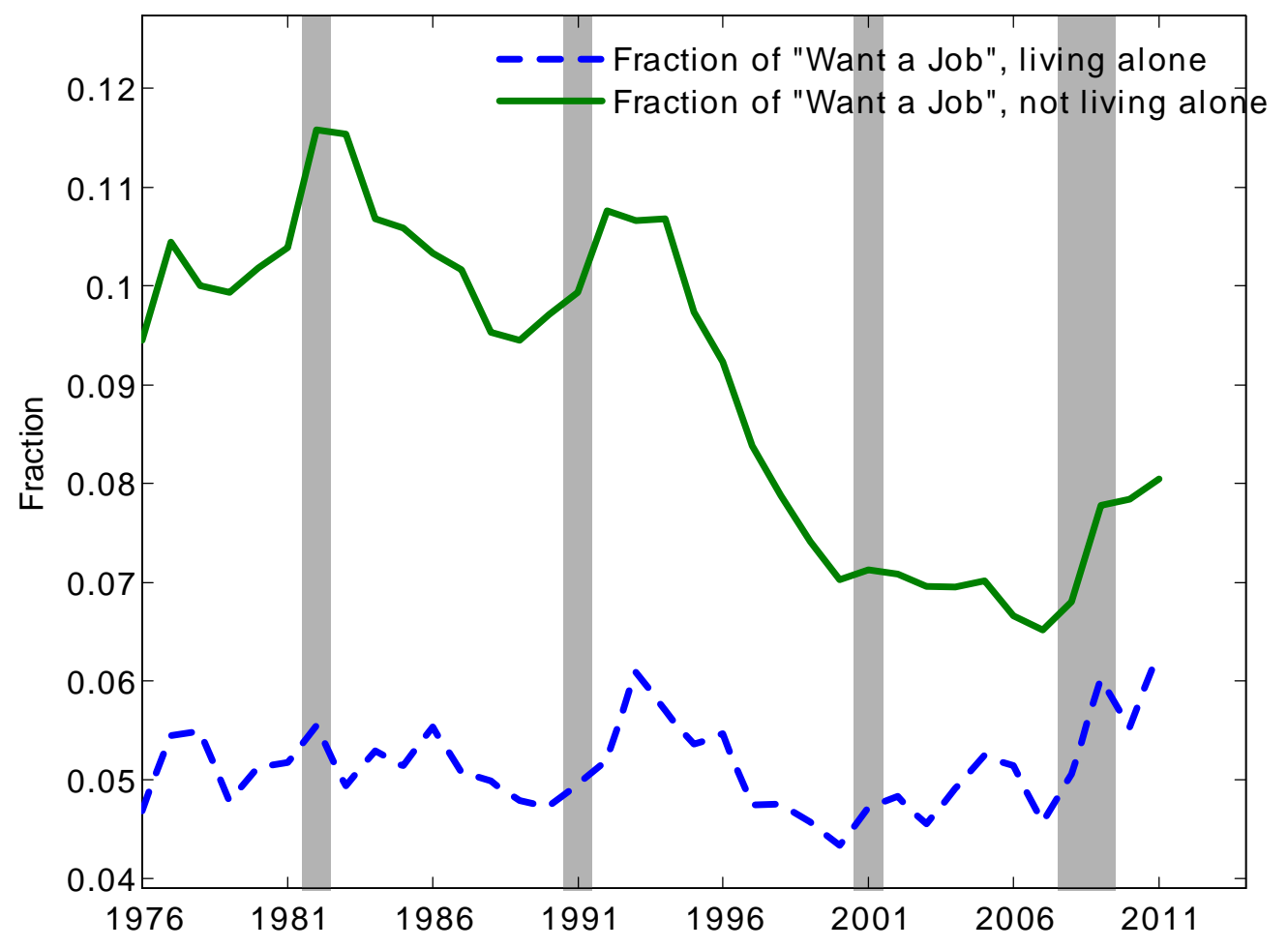

Figure 11: Fraction of nonparticipants who report "wanting a job" for nonparticipants living alone (solid line) and nonparticipants not living alone (dashed line). 1976-2011. 

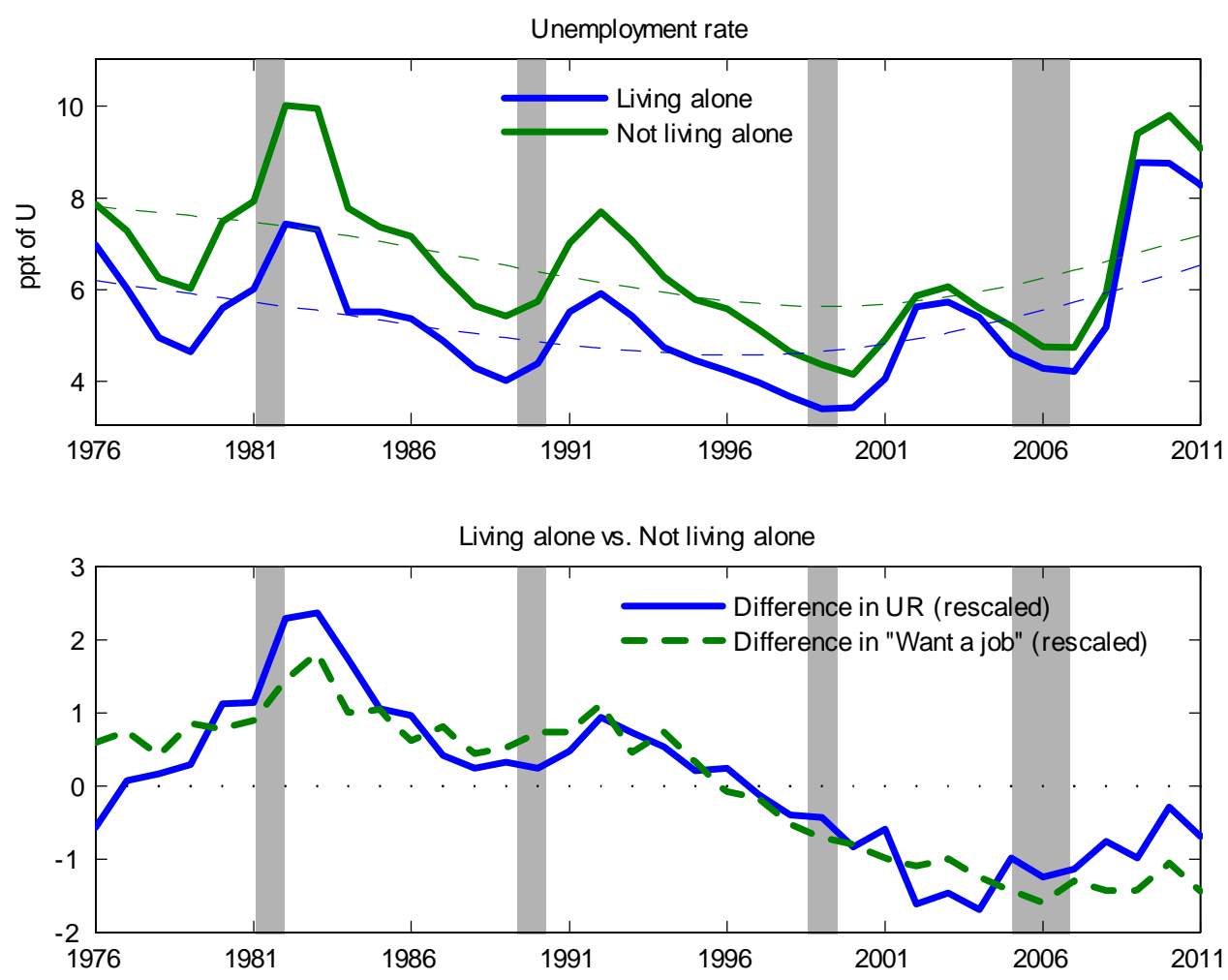

Figure 12: Top panel: unemployment rate for individuals living alone (solid line) and individuals not living alone (dashed line) along with their HP-filter trends $\left(\lambda=10^{5}\right.$, thin dashed lines), Bottom panel: Difference in unemployment rate (solid line) and difference in share of "want a job" nonparticipants (dashed line) between individuals alone and not alone. The plotted series are 4-quarter moving averages. 1976-2011. 


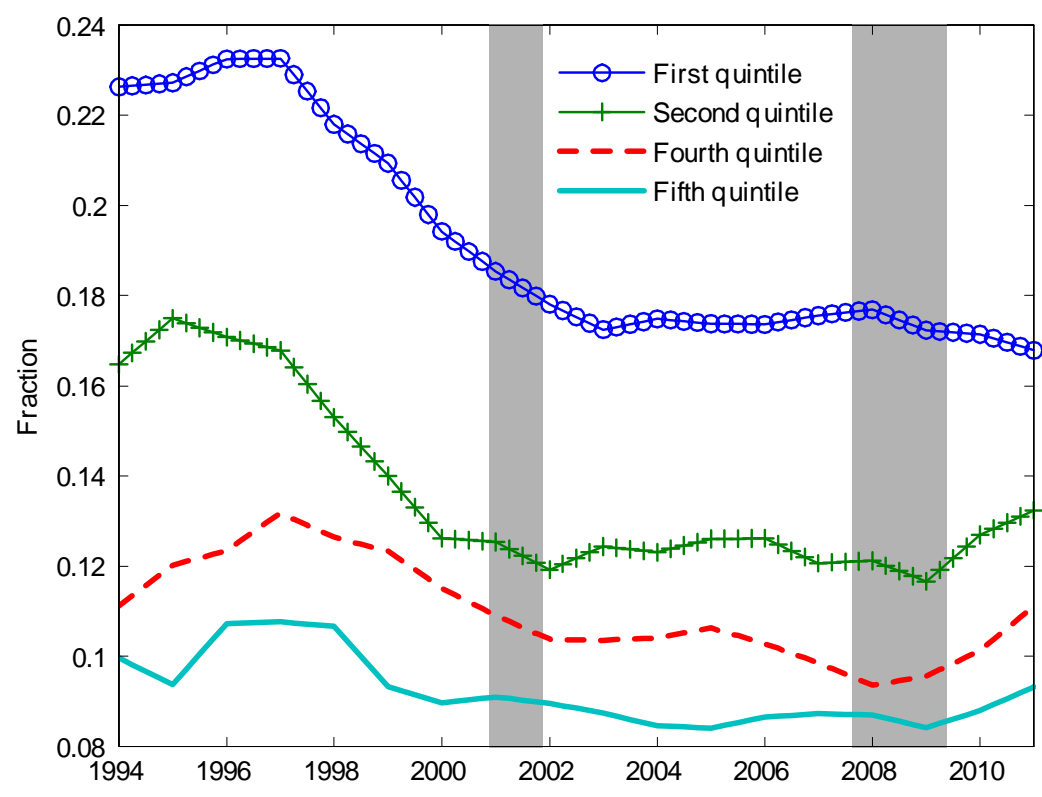

Figure 13: Fraction of nonparticipants who report "wanting a job" for individuals with family income in the first, second, fourth and fifth quintile. 1994-2011.

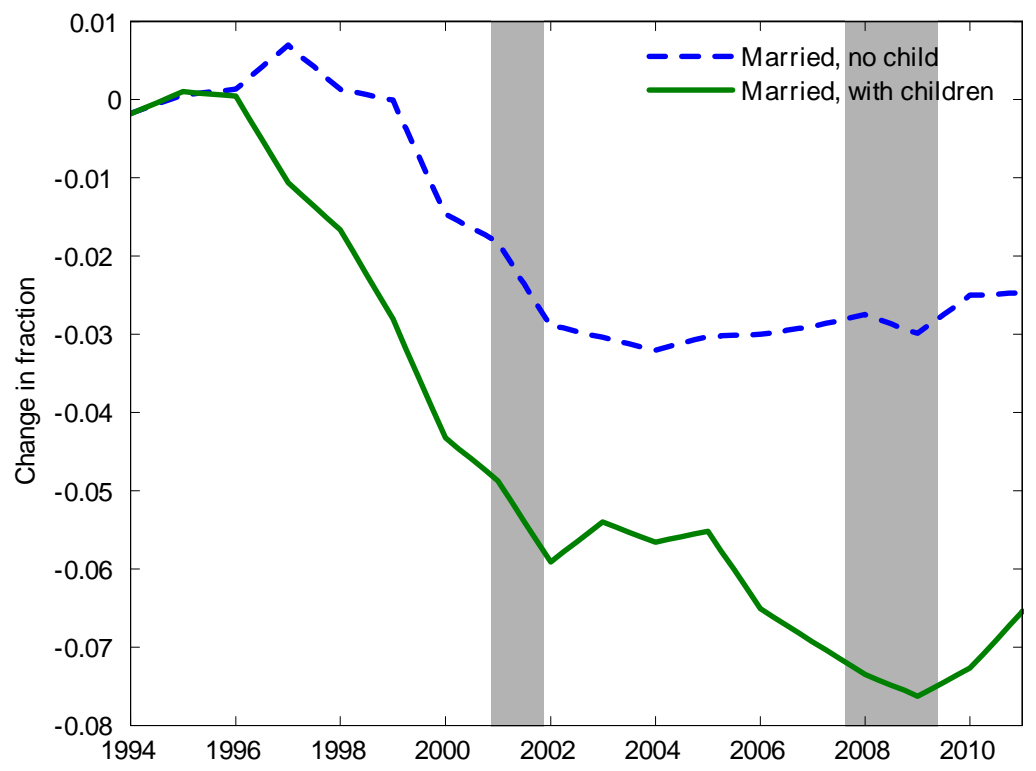

Figure 14: Changes in the fraction of nonparticipants who report "wanting a job" for married individuals with children and married individuals without children. 1994-2011. 


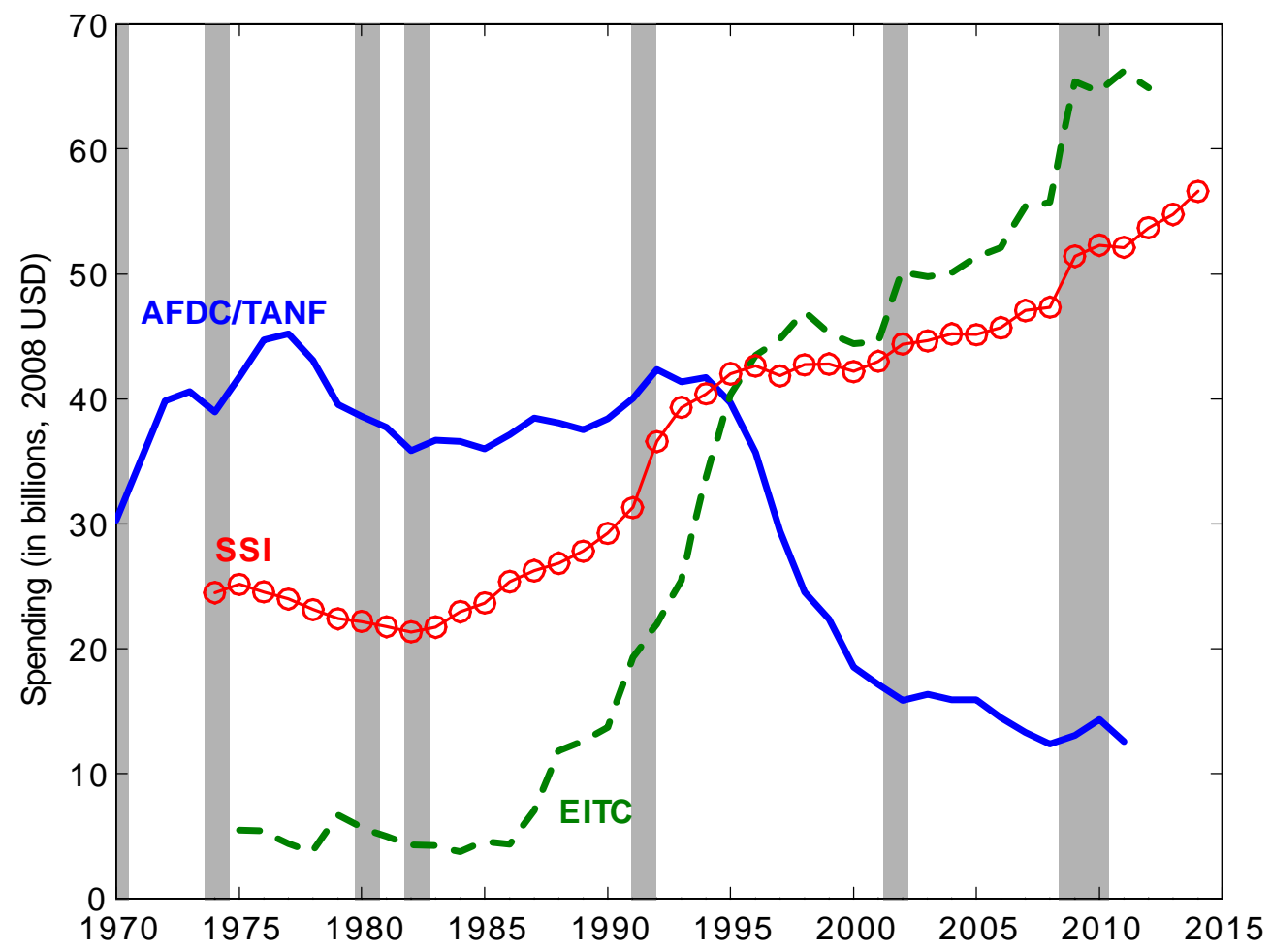

Figure 15: Welfare spending (in 2008 US\$) for the Aid to Families with Dependent Children/Temporary Assistance for Needy Families (AFDC/TANF) program, which provides cash assistance to poor families with dependent children; the Supplemental Security Income program (SSI), which pays cash to low-income people with disabilities or over 65; and the Earned Income Tax Credit (EITC), which provides a tax credit to low-to-middle income families. 


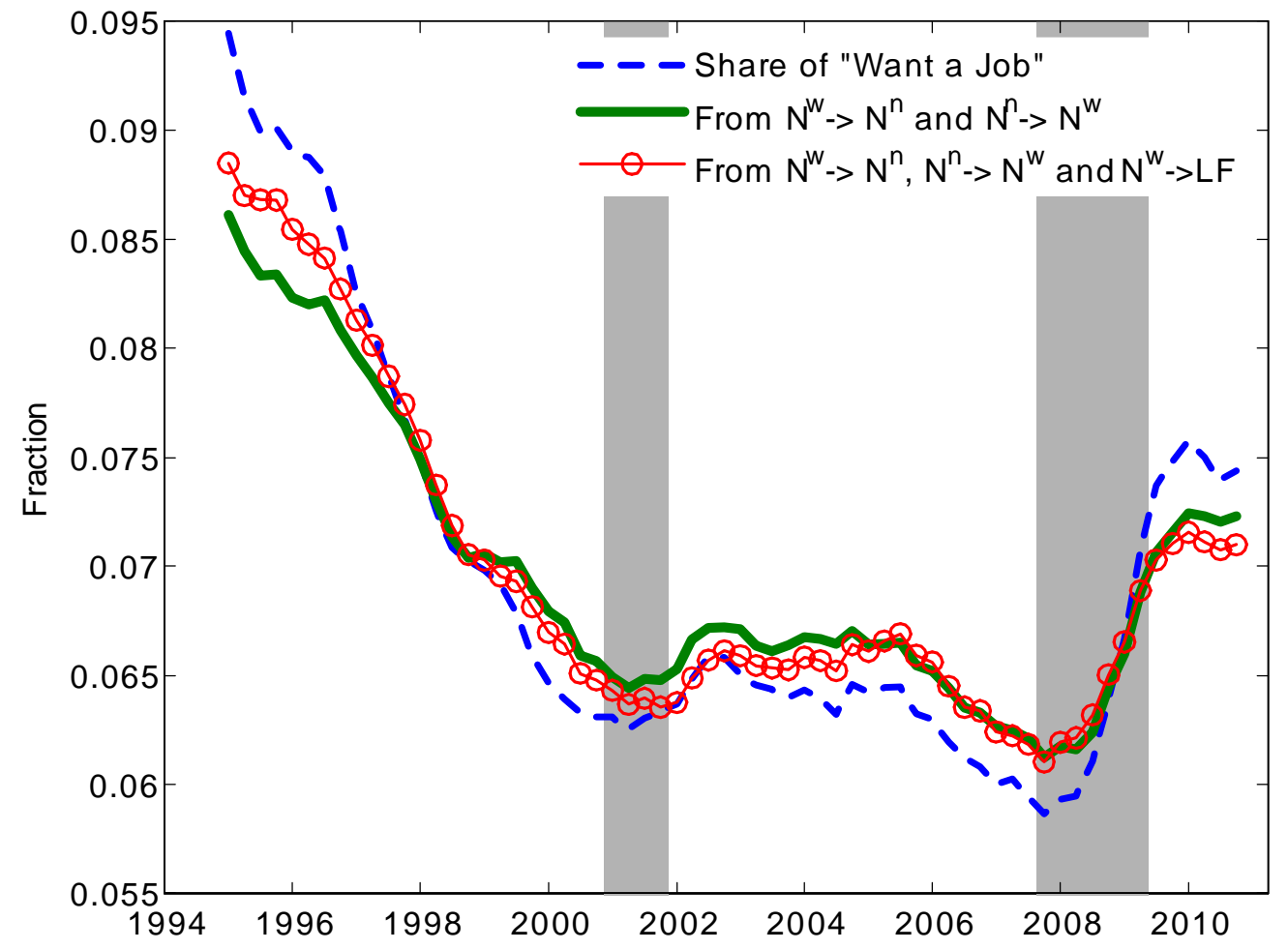

Figure 16: Share of nonparticipants who report "wanting a job" $(m)$ along with (i) the movements in $m$ generated solely by changes in the $N^{n}-N^{w}$ and $N^{w}-N^{n}$ transition rates (thick plain line) and (ii) the movements in $m$ generated solely by changes in the $N^{n}-N^{w}, N^{w}-N^{n}$ and $N^{w}-U$ and $N^{w}-E$ transition rates, labeled $N^{w}-L F$ (circled line). 4-quarter moving averages, 1994-2010. 
Table 1: Transition rates of labor force entrants

\begin{tabular}{|c|c|c|c|c|}
\hline Transitions & $\begin{array}{c}\mathbf{U N} \\
\left(\mathbf{U N}^{\mathrm{w}}+\mathbf{U N}^{\mathrm{n}}\right)\end{array}$ & $\begin{array}{c}\mathbf{E N} \\
\left(\mathbf{E N}^{\mathrm{w}}+\mathbf{E N}^{\mathrm{n}}\right)\end{array}$ & $\mathbf{U E}$ & $\mathbf{E U}$ \\
\hline Former $\mathrm{N}^{\mathrm{w}}$ & $\begin{array}{c}.44 \\
(.33+.11)\end{array}$ & $\begin{array}{c}.16 \\
(.08+.09)\end{array}$ & .20 & .08 \\
\hline Former $\mathrm{N}^{\mathrm{n}}$ & $\begin{array}{c}.57 \\
(.25+.32) \\
\end{array}$ & $\begin{array}{c}.27 \\
(.03+.24) \\
\end{array}$ & .22 & .03 \\
\hline Other & $\begin{array}{c}.19 \\
(.13+.06)\end{array}$ & $\begin{array}{c}.02 \\
(.01+.01)\end{array}$ & .27 & .01 \\
\hline
\end{tabular}

Table 2: Coefficient estimates

\begin{tabular}{|c|c|c|c|c|}
\hline & & Aggregate & $\begin{array}{c}\text { Females } \\
25-55 \\
\end{array}$ & $\begin{array}{c}\text { Young } \\
16-24 \\
\end{array}$ \\
\hline Disabled & & $\begin{array}{c}-17.2 * * * \\
(11.9)\end{array}$ & $\begin{array}{c}-13.9 * * * \\
(7.1)\end{array}$ & $\begin{array}{l}-6.4 \\
(1.2)\end{array}$ \\
\hline On welfare & & $\begin{array}{c}17.5^{* * * *} \\
(4.9)\end{array}$ & $\begin{array}{c}22.9^{* * *} \\
(5.2)\end{array}$ & $\begin{array}{l}14.4^{*} \\
(1.9)\end{array}$ \\
\hline Individual income & $\begin{array}{l}\text { Social insurance } \\
\text { Welfare income }\end{array}$ & $\begin{array}{c}-0.7 * * * \\
(9.6) \\
0.1 \\
(0.1)\end{array}$ & $\begin{array}{c}-0.6^{* * *} \\
(5.1) \\
-1.0 \\
(1.3)\end{array}$ & $\begin{array}{c}-1.5^{* * *} \\
(2.9) \\
1.4 \\
(0.6)\end{array}$ \\
\hline Family income & $\begin{array}{c}\text { Earnings } \\
\text { Social transfers }\end{array}$ & $\begin{array}{c}-4.5^{* * *} \\
(10.7) \\
-2.07 * * * \\
(3.2)\end{array}$ & $\begin{array}{c}-4.0 * * * \\
(6.6) \\
-4.4^{* * *} \\
(3.5)\end{array}$ & $\begin{array}{c}-3.9 * * * \\
(4.8) \\
-0.5 \\
(0.4)\end{array}$ \\
\hline Asset income & & $\begin{array}{l}-3.8 \\
(0.9)\end{array}$ & $\begin{array}{l}-0.7 \\
(0.9)\end{array}$ & $\begin{array}{l}-0.9 \\
(0.9)\end{array}$ \\
\hline Taxes & & $\begin{array}{c}8.3^{* * * *} \\
(3.7)\end{array}$ & $\begin{array}{l}4.5^{*} \\
(1.9)\end{array}$ & $\begin{array}{c}5.9 \\
(1.1)\end{array}$ \\
\hline Married & & $\begin{array}{c}-6.3^{* * *} \\
(15.6)\end{array}$ & $\begin{array}{c}-8.3^{* * *} \\
(14.1)\end{array}$ & $\begin{array}{c}-4.2^{* * *} \\
(4.0)\end{array}$ \\
\hline $\mathrm{Nb}$ of children & & $\begin{array}{l}-0.1 \\
(0.9)\end{array}$ & $\begin{array}{l}-0.1 \\
(0.6)\end{array}$ & $\begin{array}{c}-0.4^{* *} \\
(2.1)\end{array}$ \\
\hline $\begin{array}{l}\text { Demographic } \\
\text { controls }\end{array}$ & & Yes & Yes & Yes \\
\hline Year dummies & & Yes & Yes & Yes \\
\hline Nb. Obs. & & 65,586 & 31,960 & 23,899 \\
\hline
\end{tabular}

Note: The estimation period is 1988-2010. t-statistics are reported in parentheses. "Disabled" denotes the coefficient on a dummy equal to 1 when the individual receives disability insurance. "On welfare" " denotes the coefficient on a dummy equal to 1 when the individual receives welfare income. Demographic controls include age group, age, sex, education level, married or not, school status, position in household, and number of children. 
Table 3: Actual and predicted change in the share of "want a job" nonparticipants

\begin{tabular}{|c|c|c|c|c|}
\hline & & Aggregate & $\begin{array}{c}\text { Females } \\
25-55 \\
\end{array}$ & $\begin{array}{c}\text { Young } \\
16-24\end{array}$ \\
\hline Actual & & -4.0 & -4.4 & -5.7 \\
\hline Predicted, total & & -2.2 & -2.7 & -2.4 \\
\hline \multicolumn{5}{|l|}{ Predicted, detail } \\
\hline Demographics & & +0.6 & +0.4 & 0.1 \\
\hline \multirow{2}{*}{ Individual income } & Disability & -1.1 & -1.4 & -0.3 \\
\hline & Welfare & -1.5 & -1.8 & -1.6 \\
\hline \multirow{2}{*}{ Family income } & Earnings & -0.5 & -0.4 & -0.7 \\
\hline & Social transfers & +0.3 & +0.4 & +0.2 \\
\hline Other & & +0.0 & +0.1 & -0.1 \\
\hline
\end{tabular}

Note: "Actual" denotes the observed decline in the share of "want a job" nonparticipants between 1994 and 2006, "Predicted" reports the decline in the share of "want a job" nonparticipants as predicted by the model (excluding time fixed effects). In the category "Individual income", "Disability" combines the effect coming from the disability dummy with the effect coming from changes in the level of social insurance income, and "Welfare" combines the effect coming from the welfare participation dummy with the effect coming from changes in the level welfare income.

Table 4: Difference in difference estimates of desire to work for women with and without children

\begin{tabular}{lcc}
\hline & Married women & Single women \\
\hline Policy change & EITC & AFDC/TANF \\
Source & Eissa and Hoynes (2004) & Mc Kernan et al. (2000) \\
Eissa and Hoynes (1996)
\end{tabular}

